\title{
CAMA
}

Centre for Applied Macroeconomic Analysis

\section{Influence of renewable energy sources on transmission networks in Central Europe}

\section{CAMA Working Paper 68/2016 November 2016}

\section{Karel Janda}

Charles University, Prague

University of Economics, Prague and

Centre for Applied Macroeconomic Analysis, ANU

\author{
Jan Málek \\ Universiteit van Amsterdam, Amsterdam
}

Lukáš Rečka

Charles University, Prague

\begin{abstract}
This paper focuses on the influence of increased wind and solar power production on the transmission networks in Central Europe. To assess the exact impact on the transmission grid, the direct current load flow model ELMOD is employed. Two development scenarios for the year 2025 are evaluated on the basis of four representative weeks. The first scenario focuses on the effect of Energiewende on the transmission networks, the second one drops out nuclear phase-out and thus assesses isolated effect of increased feed-in. The results indicate that higher feeding of solar and wind power increases the exchange balance and total transport of electricity between transmission system operator areas as well as the average load of lines and volatility of flows. Solar power is identified as a key contributor to the volatility increase; wind power is identified as a key loop-flow contributor. Eventually, it is concluded that German nuclear phase-out does not significantly exacerbate mentioned problems.
\end{abstract}




\section{Keywords}

Energiewende, RES, transmission networks, congestion, loop flows, ELMOD, Central Europe

\section{JEL Classification}

L94, Q21, Q48, C61

\section{Address for correspondence:}

(E) cama.admin@anu.edu.au

\section{ISSN 2206-0332}

The Centre for Applied Macroeconomic Analysis in the Crawford School of Public Policy has been established to build strong links between professional macroeconomists. It provides a forum for quality macroeconomic research and discussion of policy issues between academia, government and the private sector.

The Crawford School of Public Policy is the Australian National University's public policy school, serving and influencing Australia, Asia and the Pacific through advanced policy research, graduate and executive education, and policy impact. 


\title{
Influence of renewable energy sources on transmission networks in Central Europe*
}

\author{
Karel Janda a,b,d, Jan Málekc, and Lukáš Rečka ${ }^{\mathrm{a}}$ \\ ${ }^{a}$ Charles University, Prague \\ ${ }^{b}$ University of Economics, Prague \\ ${ }^{\mathrm{c}}$ Universiteit van Amsterdam, Amsterdam \\ ${ }^{\mathrm{d} C e n t r e ~ f o r ~ A p p l i e d ~ M a c r o e c o n o m i c s ~ A n a l y s i s, ~ A u s t r a l i a n ~}$ \\ National University, Canberra
}

November 10, 2016

\begin{abstract}
This paper focuses on the influence of increased wind and solar power production on the transmission networks in Central Europe. To assess the exact impact on the transmission grid, the direct current load flow model ELMOD is employed. Two development scenarios for the year 2025 are evaluated on the basis of four representative weeks. The first scenario focuses on the effect of Energiewende on the transmission networks, the second one drops out nuclear phase-out and thus assesses isolated effect of increased feed-in. The results indicate that higher feedin of solar and wind power increases the exchange balance and total transport of electricity between transmission system operator areas as well as the average load of lines and volatility of flows. Solar power is identified as a key contributor to the volatility increase, wind power is identified as a key loop-flow contributor. Eventually, it is concluded that German nuclear phase-out does not significantly exacerbate mentioned problems.
\end{abstract}

\section{JEL Classification L94, Q21, Q48, C61 \\ Keywords Energiewende, RES, transmission networks, congestion, loop flows, ELMOD, Central Europe}

*Email addresses: Karel-Janda@seznam.cz (Karel Janda), janmalek.jm@gmail.com (Jan Málek), lukasrecka@gmail.com. The research leading to these results was supported by the European Union's Horizon 2020 Research and Innovation Staff Exchange programme under the Marie Sklodowska-Curie grant agreement No 681228. The authors acknowledge support from the Czech Science Foundation (grants number 16-00027S and 15-00036S), the Technology Agency of the Czech Republic grant number TD03000319 and the University of Economic, Prague (institutional support IP100040). The authors thank Warwick McKibbin for comments. Karel Janda acknowledges research support provided during his long-term visits at McGill University and Australian National University. We would like to express sincerest thanks to the company GAMS Software, GmbH which granted Jan Malek a licence for solving the model. 


\section{Introduction}

This paper investigates a contradiction between two important energy policy directions of EU: on one side creating a unified energy market, on the other side promoting renewable energy, where the problems with accommodation of renewable electricity in electricity transmission networks provide strong policy incentives to close the national networks and to refuse the transfer of electricity from other countries during high-production events (Huppmann \& Egerer 2015). In order to address this problem we use the non-linear optimization model ELMOD, which maximizes social welfare under a number of constraints We analyse the impacts of increased renewable energy feed-in and nuclear phase-out on cross-border grid congestion in Central Europe (CE) and on volatility growth in transmission networks in CE. The important contribution of this paper is that, unlike many others, it focuses on the whole region of $\mathrm{CE}$ in the same detail as Germany and particularly elaborates on the influence of individual components of German Energiewende policy (i.e. renewable energy promotion and nuclear phase-out) on the whole area. Also, this paper stresses the importance of the German - Austrian bidding zone which was mostly neglected in the previous research. This paper uses a "critical scenario approach". This means that the results must be interpreted in the context of what would be the impact of electricity flows on the grid if nothing was changed in the grid development.

On the renewable energy side of our investigated policy conflict there are EU 20-20-20 targets (European Commission 2009) and even more ambitious targets of 2030 climate energy framework (at least 40\% cuts in greenhouse gas emissions (from 1990 levels) and at least 27\% share for renewable energy and at least $27 \%$ improvement in energy efficiency) (European Commission 2014). On the market integration side of the controversy there is the effort to create a European Energy Union, officially launched in 2015 European Commission (2015). The development of variable renewable energy sources (VRES) in Germany caused severe problems with transmission network in CE region, defined as Germany, 
Czech Republic, Slovak Republic, Poland and Austria in this paper. Excess production in the north has to be transported to the consumption centres in the south of Germany, to Austria and other energy deficient countries in southern Europe. The existing German grid is not able to accommodate such a big feed-in of intermittent renewable energy and, therefore, exhibits congestion. As a result, electricity flows through the systems of adjacent countries, Poland and the Czech Republic, and this causes severe problems in their grids as well. These problems are exacerbated by the market integration, in particular by the existence of German-Austrian bidding zone which enables these two countries to trade electricity disregarding the physical grid constraints as illustrated in figure 1. While this single bidding zone also includes Luxembourg, we refer to it as German-Austrian zone because of the Central European focus of this paper.

Figure 1: Stylized map of situation in $\mathrm{CE}$

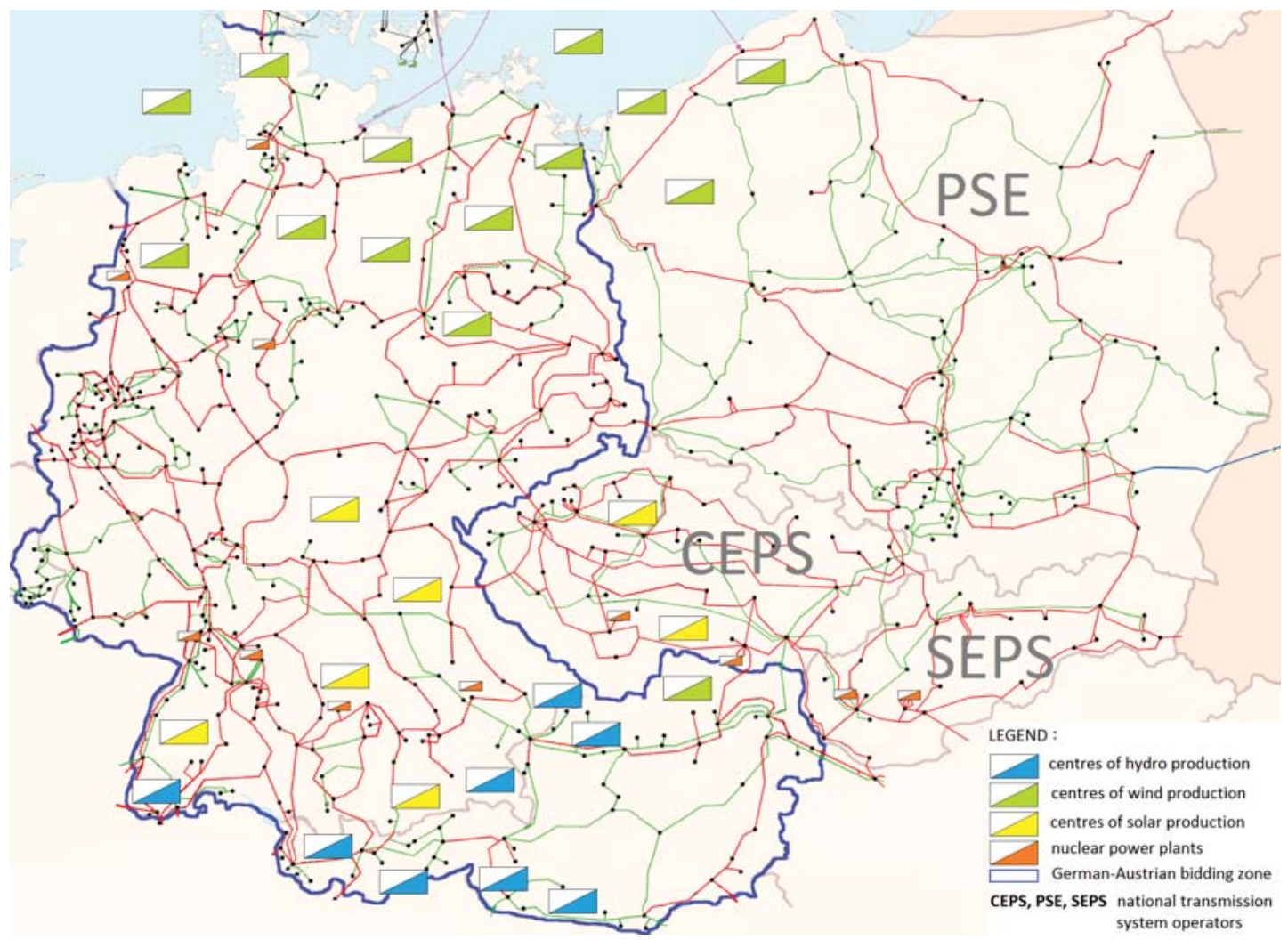

Source: Authors, based on maps from ENTSOE (2016) 
Czech and Polish transmission system operators (TSOs) react to this by the requirement of splitting up the German-Austrian bidding zone (ČEPS et al. 2012), which was also supported by the Agency for the Cooperation of Energy Regulators (ACER) (ACER 2015), or even for splitting up Germany in more zones. TSOs also attempt to solve this problem by installing phase-shifting transformers that should be able to stop the physical electricity flows in case of emergency. Nevertheless, in January 2016, the Director of DG Energy declared that European Commission is against the split of the biding zone as it considers this step to be "meaningless" (Kamparth 2016).

While many academicians conducted research on the topic of the influence of renewables on spot and forward market prices of electricity (Traber \& Kemfert (2009); Cludius et al. (2014); Ketterer (2014); Meyer \& Luther (2004)), public budgets and consumer prices (Janda et al. (2014); Průša et al. (2013)) or power system in general (Blesl et al. (2007); Havličková et al. (2011); Rečka \& Ščasný (2016; 2013); Ščasný et al. (2009)), less attention has been drawn to equally important transmission networks issues. The majority of the literature assesses the transmission network issues only in the context of Germany (Burstedde (2012); Kunz (2013); Kunz \& Zerrahn (2015); Schroeder et al. (2013); Egerer et al. (2014); Weigt et al. (2010); Dietrich et al. (2010)).

For the transmission network analysis in this paper we use the most suitable state-of-the-art model ELMOD. Since its first publication in Leuthold et al. (2008), this model has been applied most frequently to the analysis of market design (Neuhoff et al. (2013); Egerer et al. (2016b)), the influence of renewables on transmission networks (Egerer et al. (2009); Schroeder et al. (2013)) including grid and power plant investment decisions (Leuthold et al. (2009); Weigt et al. (2010); Dietrich et al. (2010); Egerer et al. (2016a)), uncertainty and stochastic effects (Abrell \& Kunz (2012)) and congestion management issues (Kunz (2013); Kunz \& Zerrahn (2015; 2016)).

The literature on transmission networks and grid in CE is significantly less 
extensive. Apart from the above-mentioned ELMOD literature, there are several other articles which mostly deal with optimal grid extension or integration of renewables into the grids. Nevertheless, these focus on Germany (Winkler et al. 2016; Singh et al. 2015) or Europe as a whole (Fürsch et al. 2013; Majchrzak et al. 2013; Schaber et al. 2012a;b). The grid related literature in Poland examined most often possibilities of phase-shifting transformers (Korab \& Owczarek 2016; Kocot et al. 2013).

The literature paying pure attention to the region of $\mathrm{CE}$ is very sparse. A few examples are very recent articles from Singh et al. (2016), analysing the impact of unplanned power flows on transmission networks, Eser et al. (2015), assessing the impact of increased renewable penetration under network development and Kunz \& Zerrahn (2016) focusing on cross-border congestion management.

The rest of this paper is structured in the following way: Section 2 provides an overview of power and transmission systems in CE. Section 3 explains the ELMOD model and the following section 4 describes the data. Section 5 introduces our base scenario and two development policy scenarios, section 6 presents and interprets the results and the last, section 7, concludes.

\section{Overview of power and transmission systems in Central Europe}

\subsection{Electricity production}

Electricity production in $\mathrm{CE}$ is heterogeneous and reflects energy reserves, potentials and policies in each country of this region. Figure 2 illustrates the differences in the generation structure among the CE countries in 2014 (2015 in case of Germany).

Out of 651.6 TWh of electricity produced in Germany during 2015 (BMWi 2016) the share of solid fuels is $42 \%$ and renewables account for $30 \%$. The most 
Figure 2: Electricity production by fuel type in CE countries

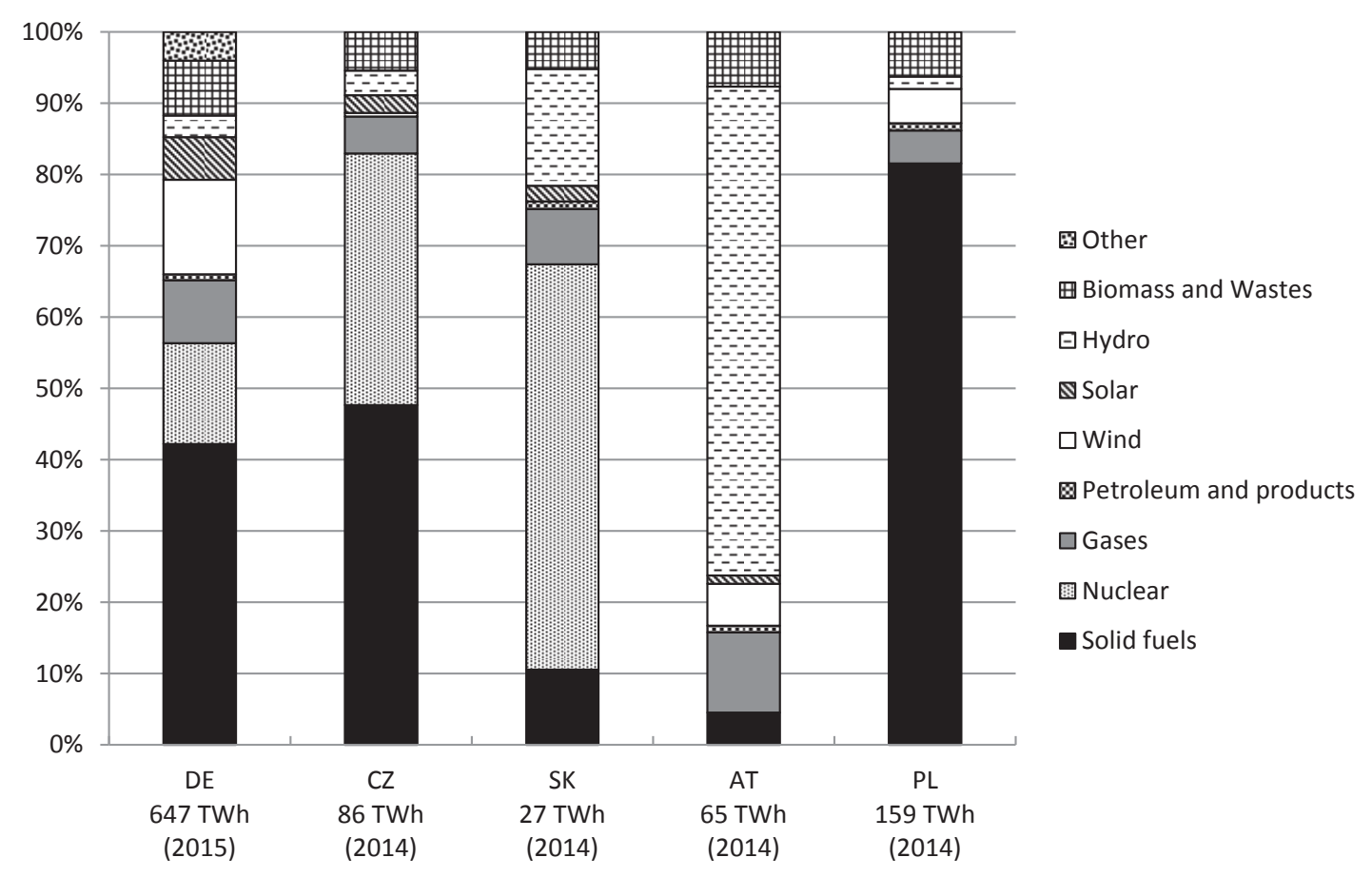

Source: European Commission, DG Energy (2016a)

important German renewable sources are on shore wind turbines, biomass and solar power plants. At the end of $2014,46.72 \%$ of total installed capacity can be assigned to renewable energy sources (RES). This is a second highest number after Austria in the CE region. Germany is a net electricity exporter since 2003 and it exported 50.1 TWh of electricity in 2015 (BMWi 2016). Due to its size, the German energy system is dominant in CE region. Thus, policies implemented in Germany affect the whole region fundamentally. This is particularly true for wind and solar production, as illustrated by the figure 3 .

Out of 86.3 TWh of electricity generated in the Czech Republic during 2014 (Energy Regulatory Office 2015) the biggest contributors were solid fuels (48\%) and nuclear power plants (35\%). At the same time, the net balance with foreign countries accounted for 16300 GWh of export which made the Czech Republic the third largest exporter of electricity in Europe (Energy Regulatory Office 2015). Moreover, the balance with other countries has not dropped under $11 \mathrm{TWh}$ since 2002 . 
Figure 3: Wind and solar production in $\mathrm{CE}^{*}$ and share of Germany

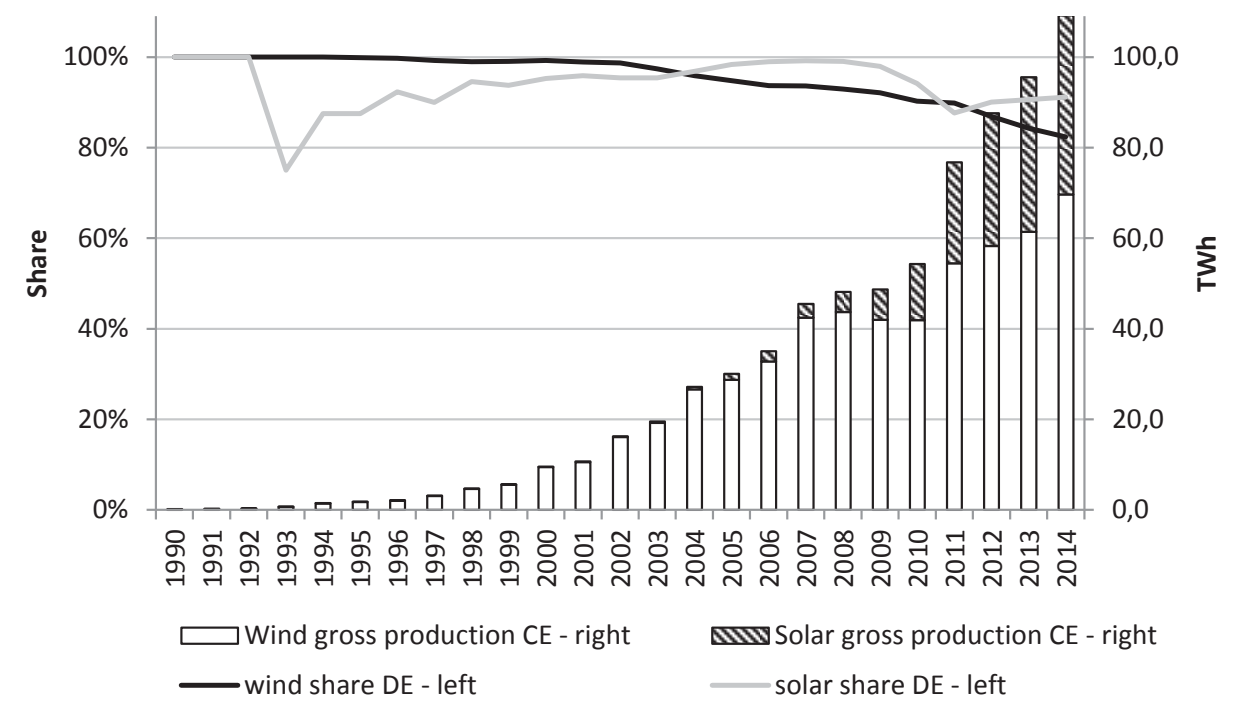

*This includes $\mathrm{CZ}, \mathrm{SK}, \mathrm{AT}, \mathrm{DE}, \mathrm{PL}$

Source: Own, data European Commission, DG Energy (2016a)

With $83 \%$ share of RES of total electricity generation (65.4 TWh in 2014), Austria is a leading nation in $\mathrm{CE}$ in ecological production. Austria is a net importer since 2001 with net electricity import of 9.275 TWh in 2014 which corresponded to $13.46 \%$ of its 2014 inland consumption (European Commission, DG Energy 2016a; E-CONTROL 2016). 2871 MW of intermittent installed capacities (wind and solar) as of 2014 corresponded to $12 \%$ of total installed capacity. It is important to note that majority of the Austrian hydro power are pumped storage power plants (7969 MW or $58.73 \%$ of installed hydro) (E-CONTROL 2016).

Slovak electricity production (27.4 TWh in 2014) as well as consumption is the lowest in the CE region. The greatest share (57\%) came from nuclear power plants and hydro power plants (16\%). Similarly to Austria, Slovakia has low share of fossil fuels on total electricity production (20\%). Slovakia is a net electricity importer since 2006 when it had to shut down part of Jaslovske Bohunice nuclear power plant. In 2014, imports accounted for 1.1 TWh which represents $3.9 \%$ of Slovak consumption. The amount of imports between different years substantially varies (European Commission, DG Energy 2016a; Ministersvo hospodárstva 
Slovenskej republiky 2015).

Out of 159.3 TWh produced in Poland in 2014, 81 \% was generated by coal fired power plants, where hard coal power plants supplied 80.24 TWh and lignite power plants 54.2 TWh (PSE 2015b). The second most utilized source were then biomass and wind power plants (6\% and $5 \%$ respectively). Especially the wind power plant installed capacity growth was significant in past years which can be mainly attributed to the fact that Baltic sea and surrounding regions offer suitable conditions for wind production. Poland is structurally an electricity exporter. Nevertheless, in 2014 we can observe imports of 2.16 TWh which accounted for $1.36 \%$ of annual consumption in 2014 (PSE 2015b).

\subsection{Transmission systems and grid development}

The German transmission grid is divided between four TSOs: TenneT, Amprion, 50Hertz Transmission and TransnetBW. The TSOs are supervised and regulated by the German federal network agency, Bundesnetzagentur (BnetzA) which ensures discrimination free grid access. Since 2011, it has also played an essential role in implementing the grid expansion codified in the Grid Expansion Acceleration Act (NABEG).

The German transmission grid faces severe congestion problems. In the past, electricity generation was based on two criteria: Availability of resources in proximity and close location to the demand. The boom of renewables has, however, changed the situation dramatically. In Germany, centres of electricity consumption are situated mostly in the south and west of Germany but regions suitable for most economic production VRES being located in the north. The electricity generated there must therefore be transported over long distances to the consumers in north-south way. In the process, the existing network is frequently reaching its capacity limits (Bundesnetzagentur 2015). This embodies clear challenge for old, supply-adjustment based grid model. More dynamic and agile set-ups including demand balancing, electricity storage devices installation and re-dispatching will 
be necessary to handle the situation successfully (Pollitt \& Anaya 2016).

The planned nuclear phaseout furthermore contributes to the north-south grid pressures. Nuclear power plants are mostly located in southern regions, Bavaria and Baden-Wurttemberg. 8386 MW of nuclear installed capacity in these two states should be disconnected from the grid by 2022. The loss of capacity is not expected to be fully offset by new installed capacities, which is the result of limited RES potential in the area (Flechter \& Bolay 2015).

The need to strengthen the infrastructure in north-south direction is therefore unquestionable which is also a stance of both, German authorities (BMWi 2015a) and especially neighboring TSOs as described bellow. The grid expansion agenda is backed by two German laws - Power Grid Expansion Act (EnLAG) from 2009 and Federal Requirements Plan Act (BBPlG) from 2013.

Figure 4: Future extension of German transmission lines

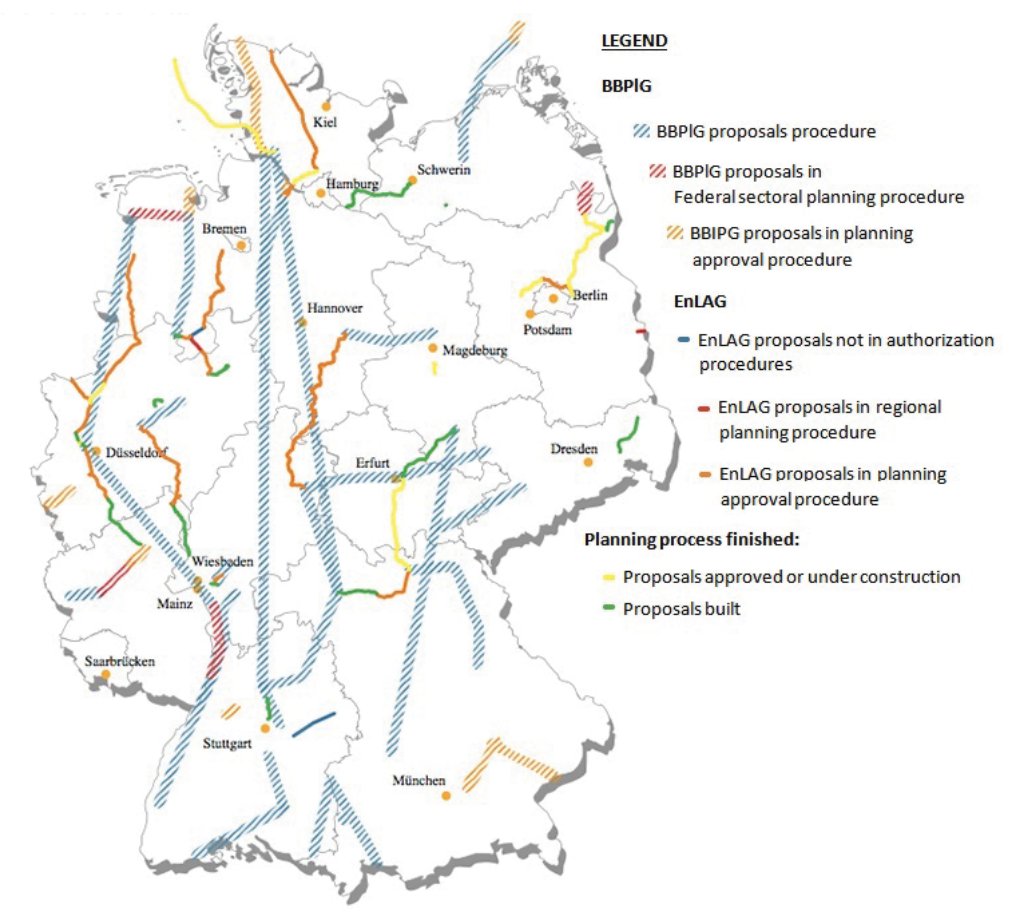

Source: BMWi (2015c)

Nevertheless, the volume of the infrastructure extension as well as the realization itself seem to be a matter of controversy and this contributes to prolongation 
of problems. EnLAG legislature specified 23 mostly north-south transmission lines in the length of $1876 \mathrm{~km}$ that need to be urgently built to preserve the stability of the system in the environment of increasing RES production. The construction should have been finished by the end of 2015 (Flechter \& Bolay 2015). Nonetheless, in the second quarter of 2015, only 8 kilometers of lines were built which provides $487 \mathrm{~km}$ with previous construction. Estimates now calculate with $40 \%$ being built till the end of 2016 (Bundesnetzagentur 2016). BBPlG, which came into effect in July 2013, added another 36 planned extension lines out of which 16 are considered of cross-regional or cross-border importance. Corridors of future networks are now determined and a public discussion about the exact tracing is in progress (BMWi 2015c). Mainly EnLAG activities suffer major project delays which can be ascribed to the negative public opinion and resistance which accompanies the network construction. The general public refuses the grid construction in the vicinity of their places of living and requires mostly the underground cable solutions. This is estimated to be up to 5 times more expensive than ordinary lines since kilometre of lines costs 1.2 Mio EUR whilst kilometre of cable costs 6 Mio EUR (Rapp 2012). As a result, it barely seems that fast short term improvement with the $40 \%$ target is foreseeable.

The Czech transmission system still reflects the design at the time of completion in the 1980s. Investments to the grid enhancement and reinforcement need to be done so that the grid is able to cope with upcoming challenges (ČEPS 2016).

Extreme growth of installed capacity of Czech solar power plants between 2008 and 2012 caused itself problems in Czech grid. In this period, the Czech cumulative solar capacity grew little more than 50 times and only during 2009 and 2010, applicants asked the distribution companies to connect up to 8000 MW (Vrba et al. 2015) which resulted in the request of Czech transmission system operator, the company CEPS, to temporarily stop the approvals of new capacities (ČEPS 2010). Thus network security was endangered already in 2010 (1727 
MW of solar and 213 MW of wind installed)(EGÚ Brno 2010) because of Czech domestic reasons. As a result, feed-in tariffs were decreased up to $50 \%$ and later were completely abolished for most RES built after 2014 (Vrba et al. 2015). After that, approvals for connections to the grid were allowed again in January 2012 (Klos 2012).

The process of planning the further development of Czech grid is mostly driven by the "Ten-year investment plan for the development of the transmission system" that works with the time scope of 2015-2024 and its main goals are expansion and upgrade of existing substations, construction of second circuits on selected lines as well as building of several new ones. Installation of phase-shifting transformers at Czech-German interconnectors should be finished till the end of 2016 with approximate cost of 74 mil EUR (ČEPS 2015). The total volume of investments during this development plan is estimated to reach 1.66 bn EUR (ČEPS 2015).

The Austrian transmission network, operated by the company APG, plays a key role in Central Europe as it is a crucial cross-road for transport of electricity from the Czech Republic and Germany to south-eastern European countries. Since 2015 the new Austrian "Ten year Network development plan" focused on grid reinforcement and expansion measures, upgrade of existing lines to higher voltage levels, construction of substation and transformers as well as $370 \mathrm{~km}$ of new transmission lines (APG 2015).

The Slovak transmission network, like the Czech one, was for a very long time part of common Czechoslovakian system which was developed together as one fully integrated system. This explains the absence of bottlenecks on the Czech-Slovak border and extraordinarily high level of interconnection of $61 \%$. The Slovak grid is important in the international context as Czech exports to Slovakia are almost fully passed further to Hungary (In 2014, 9392 GWh of electricity was imported from the Czech Republic and 9356 was exported to Hungary (Ministersvo hospodárstva Slovenskej republiky 2015)). Also the Slovak grid will be subject to reinforcements and upgrades. In 2014, SEPS issued a "Ten year 
development plan for the years 2015-2024". In this plan, investments reaching 564 mil EUR are outlined. They concern mostly internal advancement of infrastructure as well as expansion of cross-border transmission lines, particularly on Slovak-Hungarian borders. All other border profiles are not included in projected investment plans as their capacity is sufficient (SEPS 2014).

Polish transmission network suffers from very low density in northern and western areas as well as very low interconnection level of only $2 \%$ which entails severe problem when transmission of electricity is considered. Very often, congestion and hitting up of limits of the lines occur. The most critical situations appear on Polish-German border where only 4 interconnectors on the voltage level 220 $\mathrm{kV}$ are present. The contemporary "Development Plan for meeting the current and future electricity demand for 2016-2025" reacts to this and the existing interconnectors are planned to be upgraded to $400 \mathrm{kV}$ levels. Moreover, after the grid in western Poland is reinforced by 2020, new interconnector is projected after 2025. PSE also plans major infrastructure enhancement within whole Poland which is the precondition for successful connection of new expected power plants, including mostly wind, gas and coal ones. Outlays in the first half of the period should reach 1.59 bn EUR, in the second half then 1.43 bn EUR (PSE 2015a).

\subsection{Market design description and cooperation setup}

Market design is another important factor that influences power and transmission systems in CE. Under current levels of technology, possibilities of electricity storing are extremely limited when economic viability is taken into account. Consequently, flawless grid operation requires equality of supply and demand at particular time and place. TSOs are responsible for ensuring such equilibrium by forecasting demand, scheduling supply and balancing the deviations.

The design of bidding zones is an important parameter of the electricity market. Bidding zones are frequently set to correspond to national borders which reflects the nature of the infrastructure development. Setting up cross-zonal bid- 
ding areas has several advantages as well as disadvantages. The main benefits are the equality of the price of wholesale electricity in the bidding zone, higher liquidity, effectiveness and transparency of the market as well as implicit capacity allocation (ACER 2015). This is based on the fundamental assumption of sufficient transmission capacity being present within the bidding zone. The main drawback is embodied by the fact that the cross-border internal flows in a huge bidding zone cannot be controlled which implies that the flows also have an impact on adjacent bidding areas (ČEPS et al. 2012). The usual reaction of responsible TSOs is a decline of cross-zonal tradable transmission capacity (Net Transfer capacity (NTC) which is the main determinant of free cross-border commercial transmission capacities between particular zones). As such, proper bidding zone delineation is crucial for efficient functioning of the system; otherwise, such zone can represent an artificial bottleneck in the electricity market.

Austria, Germany and Luxemburg are one of the single-country bidding zone exemptions and has formed a major bidding zone in Central Europe since the year 2005. The formation was merely unilateral with no attention paid to the side-effects imposed on the adjacent countries, the Czech Republic and Poland Bemš et al. (2016). So even though the zone guarantees unrestricted trading and common electricity prices to all participating countries, lack of internal transmission capacity causes significant negative overflows to the transmission systems of neighbouring countries. Mostly for these reasons, there are attempts to split the German-Austrian bidding zone or even to split Germany into two zones to terminate the source of artificial bottleneck in the grid.

\section{Methodology}

This study applies the state-of-the-art DC load flow model called ELMOD also used in Leuthold et al. (2012) and Egerer et al. (2014). The mathematical formulation can be found in the Appendix and is based on an optimization 
problem that maximizes social welfare after taking into account the technical and physical peculiarities connected to electricity. The maximization problem is solved for the whole area at once which is equivalent to the assumption of one TSO operating entire area. The model is solved in GAMS (General Algebraic Modeling System) using the CONOPT solver.

The model applies a welfare maximizing approach with a target function maximizing consumer and producer surplus (see eq.1 in the Appendix A). The model is constrained by a nodal energy balance which states that the difference between generation and demand at a specific node, net of storage, demand shifting and load in- or outflow, must be zero (eq.3). A generation capacity constraint incorporates technical generation limits of each plant type at each node and time (eq.4). Line flow restrictions are taken into account (eq. 5)-(eq.7).

Electricity inputs include total generation from conventional power plants $\sum_{c} g_{n c t}$, wind generation $G_{n t}^{\text {wind }}$, solar generation $G_{n t}^{\text {solar }}$ and storage power plant release $P S P_{n t}^{o u t}$. Moreover, the parameter on maximum thermal limit of transmission line inherently incorporates the system security criterion by allowing for some reliability margin. The flows over particular line in a given time are modelled (eq. 5) and the phase angle for an arbitrary slack node is set to zero (eq. 7) to ensure the uniqueness of solutions (Egerer et al. 2014).

This application of ELMOD model uses a simplification of AC load flow to DC load flow model which is an approach commonly found in numerous ELMOD applications. Overbye et al. (2004) discusses the actual differences between the $\mathrm{AC}$ and DC flow applications and concludes that the loss of accuracy is very small and that DC results match pretty well AC load flow solutions. To simplify the flow calculations, ELMOD model follows the work of Schweppe et al. (1988) and Stigler \& Todem (2005) where reactive power flows and transmission lines losses are neglected, angle differences are assumed to be small and voltages are standardized to per unit levels (see Purchala et al. (2005) for applicability of these assumptions). 
As a result, DC load flow deals only with two variables - voltage angle and active power injections (eq. 8). The net input into a DC line is determined by the line flows of the DC lines multiplied by their factor in the incidence matrix.

\section{Data description}

Our dataset is based on Egerer et al. (2014) in which several adjustments and updates are made. The transmission network system, power plant units and their technical characteristics are completely taken from Egerer et al. (2014) and resemble thus the state of the year 2012. Similarly to the application of Kunz \& Zerrahn (2016), the rest of the dataset related to electricity is updated to 2015. Data for load, solar, wind, pump-storage plant generation and pumpstorage plant pumping are obtained from the ENTSOE Transparency platform (ENTSOE 2016) or from the pages of individual TSOs in case of unavailability in the Transparency platform. Prices of electricity to calculate demand are obtained from (European Commission, DG Energy 2016c). Power plant fuels prices are collected from several resources as shown in the table 1. Prices of $\mathrm{CO}_{2}$ allowances are retrieved from the database of European Energy Exchange (EEX) in Leipzig. Data on cross-country price differences in gas and oil are collected from (European Commission, DG Energy 2016d) and (European Commission, DG Energy 2016b), respectively.

\subsection{Grid}

The underlying grid data consist of nodes (transformer stations) which are connected by transmission lines (individual circuits). In several cases, auxiliary nodes are added on the intersection of lines (Egerer et al. 2014). Our dataset consists of 593 nodes, 10 country-specific nodes and 981 lines.

Each transmission line is characterized by several parameters necessary for conduction of a DC load flow model - number of circuits, length, resistance, 
reactance, voltage level and thermal limit.

There are two levels of detail in our data. First, the transmission systems of CE countries are reflected to a most possible level of detail. This means structural nature of the network is modelled by taking into account actual lines and substations which are operated by the TSOs. The exact form of the transmission system can be found in Egerer et al. (2014, p.56). The second level is more aggregate. Following Leuthold (2009), adjacent countries (all states with interconnections to the CE region: Netherlands, Luxembourg, France, Switzerland, Italy, Slovenia, Hungary, Denmark, Sweden) are represented by country-specific single nodes which are interconnected with the CE region as well as between each other. The number and properties of interconnectors between the countries are unaffected.

This distinguishes the paper from most of the research works which focus primarily on Germany and model only German network in such a detail. Another benefit is that incorporation of aggregated neighbouring states as single nodes prevents the occurrence of severe biases in resulting flows which would be the consequence of absent transit and loop flows of electricity between CE and adjacent areas. The transit flows can be illustrated on Italy, the biggest importer of electricity in Europe. Italy has terrestrial interconnections to France, Switzerland, Austria and Slovenia which supply all the imported electricity. Neglecting this would lead to inappropriate flows in the grid. Nevertheless, the applied model could be extended by at least a Balkan node as discussed in section 6.1.

The final dimension of the grid data regards security which the TSO has to take into account. In real life, this is captured by the "N-1" security criterion which is a basic criterion of power system stability. It requires that the system is able to operate and supply electricity provided a sudden outage of one system element occurs (Neuhoff et al. 2005). In the model, this security constraint is introduced by a $20 \%$ reliability margin in the thermal limit of each line (Leuthold et al. 2008, p.13). 


\subsection{Generation}

Based on the approach in Egerer et al. (2014), generation capacities are divided between conventional and renewable sources which are treated accordingly. For conventional generation, individual units or power plants are considered separately (only units above $10 \mathrm{MW}$ are considered). Each unit is allocated into one of 20 technological clusters according to fuel that is being consumed and technology that is utilized by the generation unit. Exact overview and definition can be found in Egerer et al. (2014, p.57).

The 607 generation units in the CE region are assigned to specific nodes by the method of shortest distance. In the remaining single node countries, all generation units are summed up over the production technology and allocated to that single node. Due to lack of data availability, all power plants data are taken from Egerer et al. (2014). The cost of this approach is that the generation dataset reflects the state in the year 2012. Thus an assumption about time-invariant development of generation capacities had to be made for the years 2013 to 2015. The only exception is the German nuclear phase-out which is fully reflected in the dataset for the particular period.

Actual generation from individual plants is subject to model optimization after taking technical parameters of the plants into account. These include fuel cost, generation efficiency and availability of production units. Fuel and emission prices have to be introduced as these represent the short-term variable costs of producing one MWh. This applies to conventional power plants whereas RES are considered at the zero production cost. For both types, operation and maintenance costs as well as unit commitment costs are not considered (Egerer et al. 2014). Input prices for particular inputs are given in the table 1 together with the respective data sources. All prices are updated to 2015 values except the price for coal where only 2014 values are available.

Following Egerer et al. (2014, pp.62,64) and Leuthold (2009), solar and wind power plants are aggregated regionally with respect to individual nodes. As a 
result, the weights of individual nodes on the total solar and wind generation are obtained. The renewable generation enters the model as a parameter and for this reason, aggregate data on 2015 hourly generation for the country level are obtained from ENTSOE transparency platform. These are then allocated to individual nodes in accordance with the aforementioned approach.

Table 1: Fuel prices

\begin{tabular}{lcl}
\hline Fuel & Price & Source \\
& {$\left[\mathrm{EUR} / \mathrm{MWh}_{t h}\right],\left[\mathrm{EUR} / \mathrm{t}\left(\mathrm{CO}_{2}\right)\right]$} & \\
\hline \hline Uranium & 3 & Assumption of Egerer et al. (2014) \\
Lignite & 3,48 & Own calculation \\
Hard Coal & 6,96 & BP: Northwestern Europe coal price 2014 \\
Gas & 22,28 & EC: Quarterly reports on European gas markets \\
Oil & 28,42 & Bloomberg: Brent oil price \\
Biomass & 7,2 & Assumption of Egerer et al. (2014) \\
Hydro & 0 & \\
Wind & 0 & \\
Sun & 0 & \\
Waste & 7,2 & Assumption of Egerer et al. \\
Carbon & 7,59 & EEX: Median CO2 EUA settlement prices \\
\hline
\end{tabular}

Table 2 shows the technology-specific efficiencies with respect to time and technology.

Table 2: Efficiency of conventional generation technologies (in \%)

\begin{tabular}{lccccccc}
\hline & 1950 & 1960 & 1970 & 1980 & 1990 & 2000 & 2010 \\
\hline \hline Nuclear & 33 & 33 & 33 & 33 & 33 & 33 & 33 \\
Lignite & 29 & 32 & 35 & 38 & 41 & 44 & 47 \\
Coal & 29,6 & 32,8 & 35,9 & 39,1 & 42,3 & 45,5 & 48,7 \\
CCGT and CCOT & 20 & 26,7 & 33,3 & 40 & 46,7 & 53,3 & 60 \\
Gas Steam and Oil Steam & 30,6 & 33,8 & 36,9 & 40,1 & 43,3 & 46,5 & 49,7 \\
OCGT and OCOT & 24,7 & 27,3 & 29,9 & 32,5 & 35,1 & 37,7 & 40,3 \\
\hline Source & (Egerer et al. 2014, p.70) & & & \\
\hline
\end{tabular}

Availability parameter can be found in the table 3. Availability of wind, solar and pump storage power plants is set to one as corresponding data enter the model as external parameters. 
Table 3: Availability of conventional generation technologies

\begin{tabular}{lllllllll}
\hline Type & Nuclear & Lignite & Coal & $\begin{array}{l}\text { CCGT, } \\
\text { CCOT }\end{array}$ & $\begin{array}{l}\text { OCGT, } \\
\text { OCOT }\end{array}$ & $\begin{array}{l}\text { Gas Steam, } \\
\text { Oil Steam }\end{array}$ & $\begin{array}{l}\text { Reservoir, } \\
\text { RoR }\end{array}$ & Hydro \\
\hline \hline Availability & 0,84 & 0,9 & 0,87 & 0,91 & 0,9 & 0,89 & 0,62 & 0,32 \\
\hline Source: & Egerer et & al. $(2014$, p.70) & and Schröder et al. $(2013)$ & & \\
\hline
\end{tabular}

\subsection{Load and electricity price}

ENTSOE database is the source of hourly data for all included countries for the year 2015. Primary need for the load data is based on the necessity to have the counterpart to the generation on nodal basis in CE region and national basis in the rest of countries. However, the load values are available on national level only which is not satisfactory for the purposes of the model. Egerer et al. (2014) suggests to use GDP and population as proxies for industrial and residential demand respectively (GDP assumes $60 \%$ weight whereas population assumes $40 \%$ ). All data are taken on the NUTS 3 level, for which the data are available in all cases (Egerer et al. 2014). Exact allocation procedure is described in detail in Egerer et al. (2014) and Leuthold et al. (2012).

Secondary utilization of the load data occurs in the optimization problem where the welfare function is maximized. At each node, reference demand, reference price and elasticity are estimated in order to identify demand via a linear demand function (Leuthold et al. 2012). In here, as Leuthold suggests, the hourly load is assigned to the nodes according to the node's share described earlier. This, subsequently, yields a reference demand per node. Table 4 shows the prices for relevant countries.

Table 4: Electricity reference prices, [EUR/MWh]

\begin{tabular}{llllllllllllllll}
\hline Country & AT & CH & CZ & DE & DK & FR & HU & IT & LU & NL & PL & SI & SK & SE \\
\hline \hline Price & 32,33 & 36,80 & 32,53 & 32,08 & 25,63 & 38,75 & 41,45 & 53,80 & 32,08 & 41,73 & 41,48 & 41,93 & 33,50 & 18,51 \\
\hline Source: & European Commission, DG Energy $(2016 \mathrm{c})$ & & & & & & & & & \\
\hline
\end{tabular}

Demand elasticity is taken as -0.25 based on Green (2007). 


\subsection{Simplification of the full year model}

Due to computational limitations resulting from complex structure of the model, four representative weeks with the different combinations of extreme values of RES production are used and investigated in detail. Similarly to Schroeder et al. (2013), four weeks (we use English-type weeks, i.e. the week starts by Sunday) with different values of wind and solar production are chosen. In particular, we speak about two base weeks, week 4 (penultimate week in January - from 18th January to 24th January) and week 14 (last week in March - from 29th March to 4th April), where the cumulative production from wind and sun is lowest or highest in CE, respectively. The two other weeks, 27 (last week in June from 28th June to 4th July) and 49 (last week in November from 29th November to 5th December), were considered only as a robustness check for our results as they mirror the opposite extremes in production. Thus, week 27 mirrors the situation provided there is a high production from sun and low production from wind and week 49 reflects the opposite.

In the figures 5 and 6 , the aggregate load-generation profiles for $\mathrm{CE}$ countries during the base weeks are shown on the real data for 2015. Load, residual load, where Residual load = Load - Sun generation - Wind generation, sun and wind generations are depicted during the respective hours of the week.

Figure 5: Week 4 profile

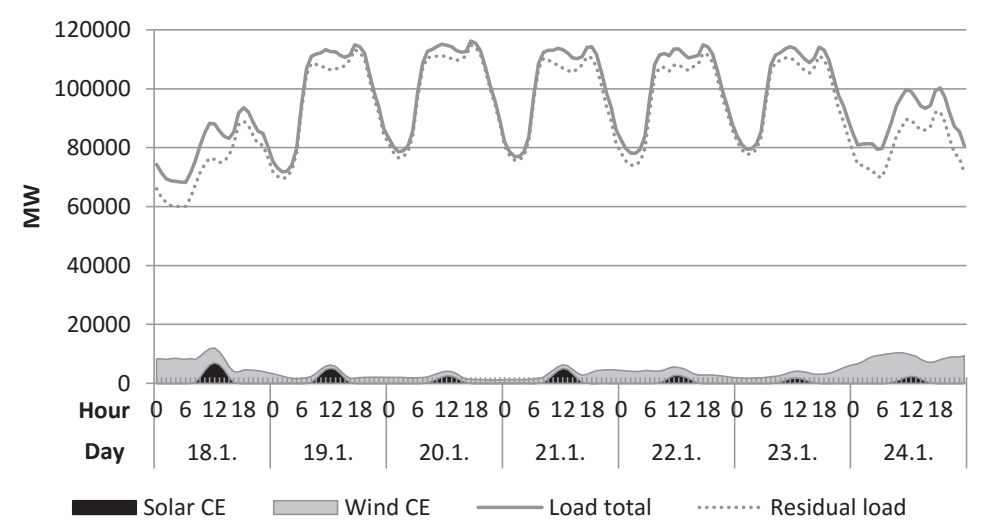


Figure 6: Week 14 profile

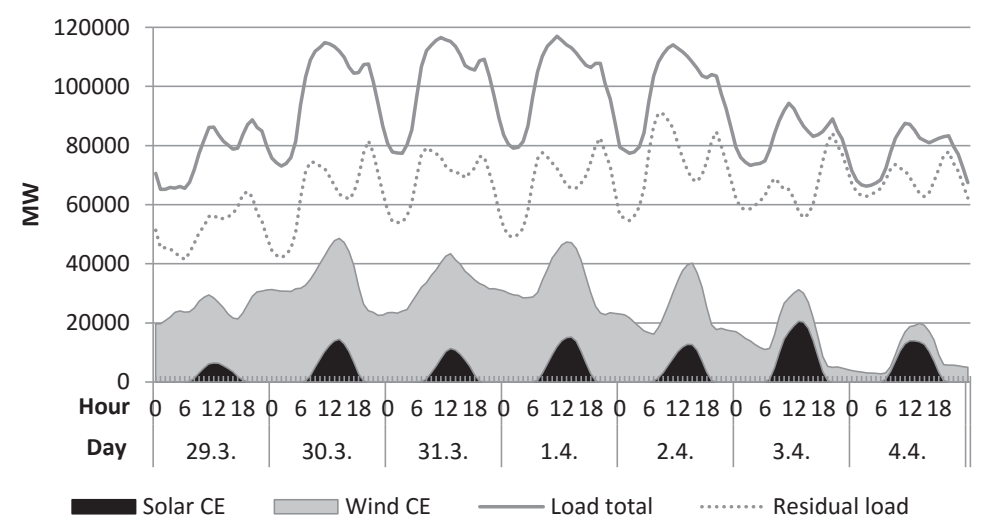

Source: Own, based on ENTSOE (2016) data

\section{Scenarios}

To measure exactly the impacts of grid bottlenecks between southern and northern Germany and Energiewende policy on the transmission grid, electricity flows over the individual lines within the network are obtained. Afterwards, they are compared in the context of three scenarios.

Reference scenario, called base, models the current situation in the power sector based on the data as specified in section 4 .

Scenario full assesses full range of the impacts of increase of VRES production and nuclear phase-out in CE context. It is derived from the base scenario by taking into account the aims of German energy policy for the year 2025. Parameters reflecting the VRES production are multiplied by coefficients (table 5) and nuclear power plants are phased-out. Everything else in Germany as well as in remaining countries, including grids, reflect the state of 2015 or other years as specified in the section 4 . From the nature of construction the results must be read in the context of worst possible outcome if nothing was done in network development.

All relevant electricity-related Energiewende goals are defined as a percentage of electricity consumption as compared to the year 2008. According to 
AGEB (2015), 618.2 TWh of electricity was consumed in Germany in 2008. Energiewende goals require the electricity consumption to be reduced by $10 \%$ until 2020 and by 25\% until 2050 (BMWi 2015b). Linear approximation leads to $12.5 \%$ reduction in 2025 which accounts for 541 TWh. This comprises $90.61 \%$ of the 2015 consumption.

Shares of solar and wind electricity generation are based on the scenario "2025 A" from "Netzentwicklungsplan" (Feix et al. 2015) where installed capacities are projected. Actual generation is obtained by multiplying these figures by utilization factors of individual power plant types extracted from AGEB data. This approach yields the renewable/consumption ratio of $45.91 \%$, pretty close to $42.5 \%$ which is the result of linear approximation for year 2025 using BMWi scenarios (BMWi 2015b). Table 5 summarizes the calculations concisely.

Table 5: Parameters of full scenario model

\begin{tabular}{|c|c|c|c|c|c|c|c|}
\hline TYPE & $\begin{array}{c}\text { Installed capacity } \\
2013 \text { (MW) } \\
\text { (1) }\end{array}$ & $\begin{array}{l}\text { Development } \\
\text { coefficient } \\
(2)\end{array}$ & $\begin{array}{c}\text { Installed capacity } \\
2025 \text { (MW) } \\
\text { (3) }\end{array}$ & $\begin{array}{l}\text { Full load } \\
\text { hours } \\
(4)\end{array}$ & $\begin{array}{c}\text { Generation } \\
2025(\mathrm{TWh}) \\
(5)\end{array}$ & $\begin{array}{l}\text { Generation } \\
2015 \mathrm{TWh} \\
\quad(6)\end{array}$ & $\begin{array}{l}\text { Generation } \\
\text { coefficient } \\
\quad(7)\end{array}$ \\
\hline Solar & 36340,00 & 1,490 & 54159,61 & 969,77 & 52,52 & 38,50 & 1,364 \\
\hline Wind onshore & 33310,00 & 1,568 & 52231,66 & 1900,46 & 99,26 & & \\
\hline Wind offshore & 620,00 & 14,355 & 8900,00 & 3118,28 & 27,75 & & \\
\hline Wind & 33930,00 & & 61131,66 & & 127,02 & 86,00 & 1,477 \\
\hline Biomass & 8380,00 & 1,032 & 8650,32 & 5000,00 & 43,25 & 44,30 & \\
\hline Water & 5590,00 & 1,000 & 5590,00 & 3494,62 & 19,53 & 19,50 & \\
\hline Other & & & & & 6,00 & 5,70 & \\
\hline Source: & Feix et al. (2015) & Feix et al. (2015) & $(1)^{*}(2)$ & $\begin{array}{c}\text { Own, } \\
\text { data BMWi (2015b) }\end{array}$ & $(3) *(4)$ & AGEB (2015) & $(5) /(6)$ \\
\hline
\end{tabular}

Values given in the column "Generation coefficients" are then that ones, by which original data for wind and solar production are multiplied. Finally, BMWi scenario was selected because it is highly probable that policy makers will stick to it and will thus follow time-consistent development based on this scenario. This assumption is based on two findings: first, the BMWi scenario exhibits extraordinarily high social acceptance when compared to other development scenarios (Schubert et al. 2015b), and, second, it focuses highly on economic viability and emission reduction (up to $80 \%$ as of 1990 (Keles et al. 2011)) which are both factors playing major role in German public's opinion on Energiewende (Schubert et al. 2015a). 
Scenario res inspects one particular part of Energiewende policy - the nuclear phase-out or, from the other point of view, isolated impact of renewables on transmission networks without the nuclear phase-out. It is based on full, except the fact that German nuclear power plants are considered to be still in operation even after 2022 .

\section{Results}

The results are presented for the two base weeks with low and high VRES production. There are 30 interconnectors between the countries of Central Europe, 29 interconnectors between the German TSOs, another 39 interconnectors between the Central Europe and adjacent states and hundred of lines within the particular countries. Commentary on each individual line would not contribute to a lucid and clear interpretation of results. Hence, resulting modelled flows are reported and interpreted on "border profiles" as in Egerer et al. (2014). (Full access to aggregated results is provided in supplemental materials available upon request).

There are three kinds of border profiles considered in this paper: border profiles between countries, border profiles between TSOs within Germany, and border profile between northern and southern Germany. This northern-southern Germany border profile is employed for the examination of the electricity exchanges with respect to the bottlenecks within Germany as described in the section 2 . This border profile is created similarly to the study of Egerer et al. (2016b).

Detailed commentaries are made only for the weeks 14 and 4 where peak and bottom of cumulative VRES production occurred, respectively. We do not report the results for the weeks 27 and 49 as they quantitatively confirm he results for weeks 4 and 14. From the qualitative perspective, these results match the reality pretty well. Brief overview of these results can be found in supplementary materials. Eventually, res and full scenarios are compared with the base scenario. 
Percentage changes in transmission (sum of absolute values of import and export over the interconnector) and absolute value of changes of balances (difference between import and export keeping the flow direction) and transmission are presented together in table 6 . Table 7 gives then an overview of extreme loads which are defined as a number of times the flow over particular line exceeds $75 \%$ thermal limit of the line. Each line is subject to a $20 \%$ margin representing the "N-1" criterion of security. Thus, if the line exceeds $75 \%$, it could be considered as critical event.

\subsection{Week 4 - low VRES production}

The general effect of low VRES production is the low international balance as well as total transmission of electricity (fig. 7 - 8).

Figure 7: Transmission DE, W4

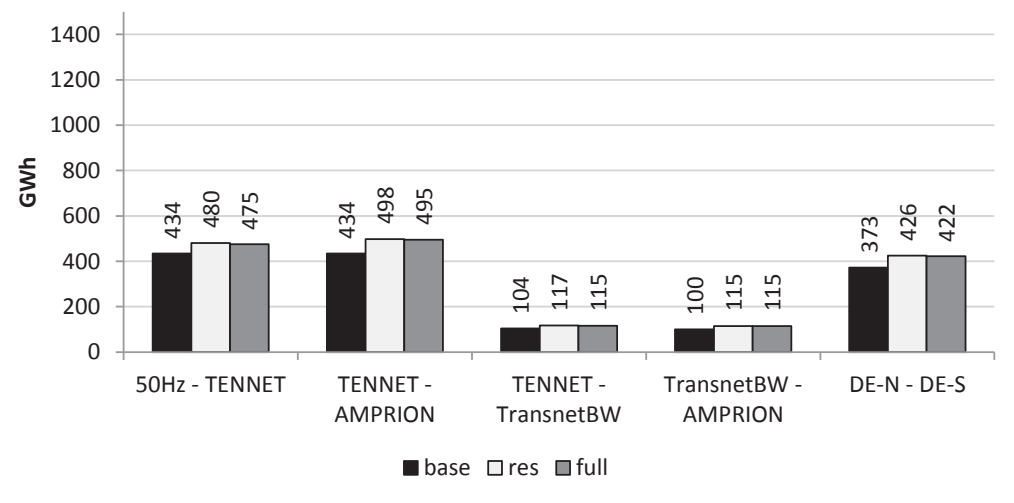

The base scenario results for exchange balance fit the actually observed ones, except the case of Czech-Slovak and Polish-German borders. Despite this fact, week 4 results exhibit quite a poor performance in predictions of amounts. Table 6, column 1, summarizes the proportional deviation from real balances. The opposite flow directions in the cases of Czech-Slovak and Polish-German borders are represented by the values lower than $-100 \%$. Reversed flow on Czech-Slovak border is structural in the model due to the fact that electricity flows from the 
Figure 8: Transmission CE, W4

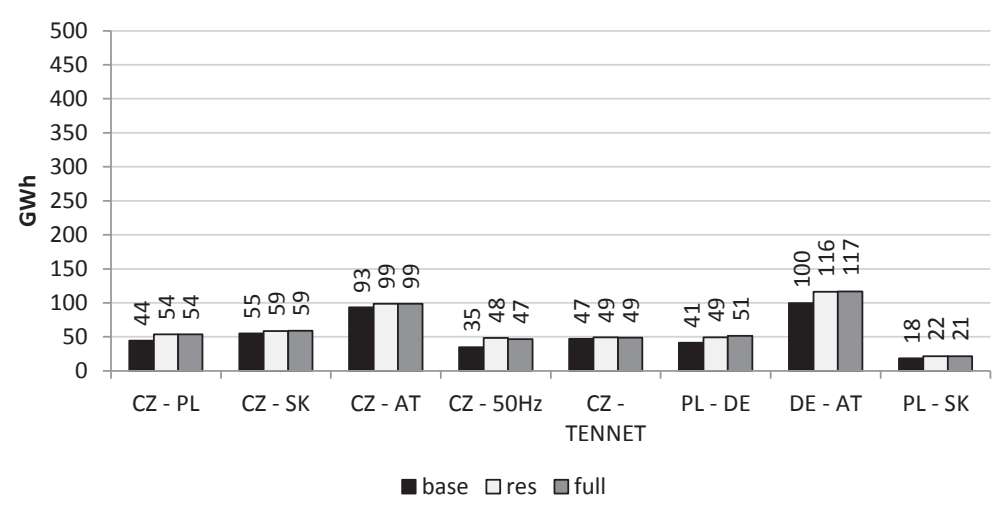

Czech Republic through Slovakia to Hungary and further to Balkan countries in the reality. In the model, the Balkan countries are not modelled which results in above mentioned consequence. Problem could be solved in future by adding up Balkan countries as one additional importing node.

The poor model prediction performance in this particular week with low load might be linked to the single TSO's area nature of the model. As low share of zeromarginal cost renewable production enters the model, non-zero cost conventional production has to take place to meet the demand. Because of the single TSO in the model, all area is optimized at once. Therefore, conventional power plants produce at the most possible local level and the necessity for cross-zonal transport of electricity is limited. Furthermore, similar predictive power of the model was found also in other studies, e.g. in Egerer et al. (2014).

Comparison of the scenarios res and full does not confirm the anticipated negative impacts on the grid of nuclear phase-out in the sense of exacerbating the overloading of grids in the north-south direction in Germany and in sense of greater loop flows through Poland and the Czech Republic (table 6, figures 7 and 8). Average utilization of cross border-interconnectors is very low (below 20 \%) as a result of low amount of transport as explained in previous paragraphs. Even though some increase of utilization can be observed on all but three lines, the increase is very modest. The maximal rise of $6,56 \%$ is measured over the line 
Krajnik (PL)-Vierraden (DE).

The results also confirm that VRES induce growth of volatility of transmission and, consequently, contribute to the system destabilization. All but three lines evince standard deviation increment and thus more fluctuating flows can be observed. Unlike in the previous case with the average load, the degree of volatility differs between res and full scenarios. In both cases, the higher degree of volatility can be observed, but nuclear phase-out in full scenarios further aggravates it.

Within the scope of week 4, only one critical event, when the flow on the particular line exceeds $75 \%$ thermal limit of the line, occurs on the line KrajnikVierraden (table 7). This is due to the fact that the general load is very low in this week.

\subsection{Week 14 - high VRES production}

The qualitative nature of the results for this week is essentially the same as for week 4. Nevertheless, the magnitudes and strengths of effects are notably larger. Actual total transmission average rose 2.54 times, maximal relative one increased about 3.41 times (CZ-Tennet profile) and maximal absolute one grew by $670.3 \mathrm{GWh}(50 \mathrm{~Hz}$-Tennet profile).

Figure 9: Transmission DE, W14

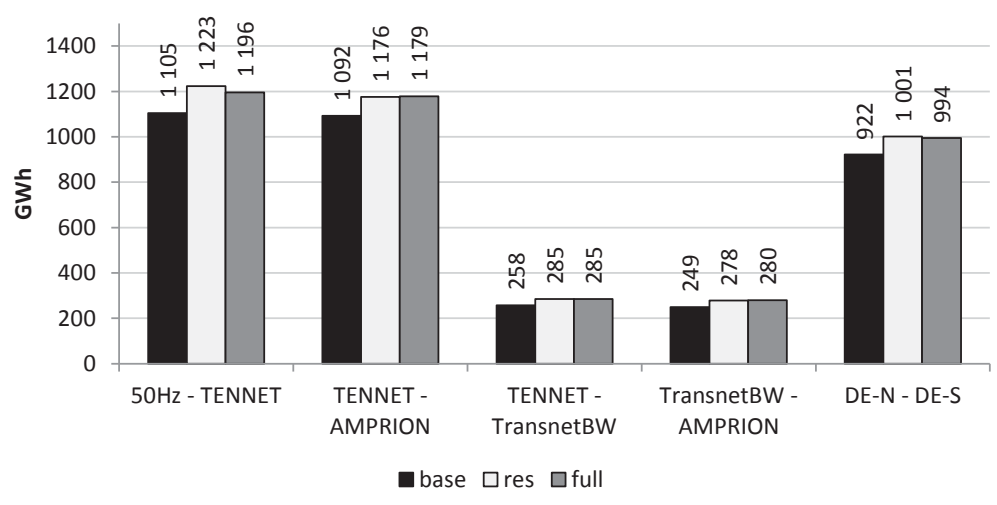


Figure 10: Transmission CE, W14

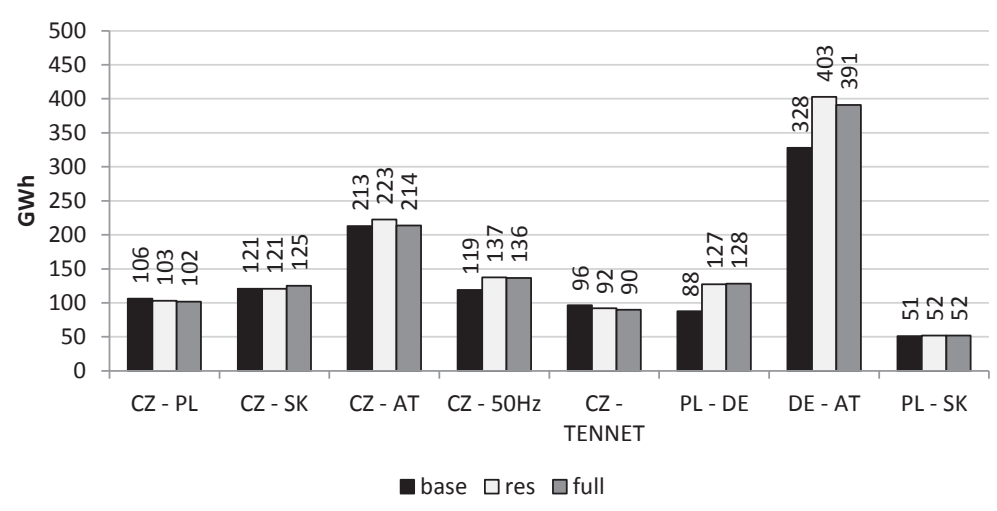

The comparison of real balances to the modelled ones yields much more satisfactory results as can be seen in table 6 .

Scenarios res and full yield both higher exchanges and larger amount of transmitted electricity as compared to base but again the influence of nuclear phaseout, i.e. the difference between res and full flows, is counter-intuitive. Flows in full are actually almost the same or lower than in the case of res but they were originally expected to be much higher. It is very likely that the answer to this question is hidden in the merit order effect. When base-load and cheaply operating nuclear power plants are shut down, electricity supply curve shifts to the left resulting in higher price. This incentivizes more flexible but more expensively operating hard-coal, gas or even oil power plants to produce and supply locally and flexibly the electricity which can smooth the VRES volatile production. These amounts cannot be naturally enough to equilibrate all the increase in volatile production but they can significantly milder it. The exact effect of the smoothing (and consequently the amount of electricity transport) depends on the magnitude of the merit order shift and on the increase of the production from mentioned conventional power units. These merit order price-related effects are not exactly measured in this paper as they exemplify completely independent research question.

Within the scope of the week 14, roughly $10 \%$ increase occurs on profiles 
in Germany (fig. 9) in scenarios res and full compared to base scenario. The other profiles exhibit various behaviour, ranging from slight decreases to immense growths (fig. 10). German-Austrian and German-Polish border profiles face 46.5 $\%$ and $19.2 \%$ transmission increase, respectively, when full scenario is considered. Also the average load on particular lines on these profiles rose (Krajnik-Vierraden even by $18.2 \%$ ). Intuitively, this is also accompanied by the upturn in critical events growing cumulatively by 16 on all 13 DE-AT lines and by 27 on only two $50 \mathrm{~Hz}-\mathrm{PL}$ lines as compared to the base situation (table 7 ).

Growth of standard deviation can be observed on the base-res basis as well as on the base-full basis on all but two border lines. Also the res-full comparison shows rise in volatility on majority of lines. In all three cases, particularly interconnectors between Germany and Austria are under the biggest volatility pressure; highest values achieve $50 \%$ increase.

Table 6: Weekly changes

\begin{tabular}{|c|c|c|c|c|c|c|c|c|c|c|c|c|c|c|}
\hline \multirow[b]{2}{*}{ Border profile: } & \multirow[t]{2}{*}{$\begin{array}{l}\text { Model vs. real } \\
\text { bal. deviation* }\end{array}$} & \multicolumn{2}{|c|}{$\begin{array}{l}\text { Balance increse } \\
\text { GWh }\end{array}$} & \multicolumn{2}{|c|}{$\begin{array}{l}\text { Transmis. increase } \\
\text { from the base, GWh }\end{array}$} & \multicolumn{2}{|c|}{$\begin{array}{l}\text { Transmis. increase } \\
\text { from the base, } \%\end{array}$} & \multirow[t]{2}{*}{$\begin{array}{l}\text { Model vs. real } \\
\text { bal. deviation* }\end{array}$} & \multicolumn{2}{|c|}{$\begin{array}{l}\text { Balance increse } \\
\text { GWh }\end{array}$} & \multicolumn{2}{|c|}{$\begin{array}{l}\text { Transmis. increase } \\
\text { from the base, GWh }\end{array}$} & \multicolumn{2}{|c|}{$\begin{array}{l}\text { Transmis. increase } \\
\text { from the base, } \%\end{array}$} \\
\hline & & res & full & $\begin{array}{l}\text { w4 } \\
\text { res }\end{array}$ & full & res & full & & res & full & $\begin{array}{c}\text { w14 } \\
\text { res } \\
\end{array}$ & full & res & full \\
\hline CZ - PL & $-82,4 \%$ & $-5,37$ & $-6,97$ & 9,31 & 9,34 & $21,0 \%$ & $21,1 \%$ & $-24,5 \%$ & $-6,51$ & $-7,36$ & 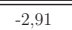 & $-4,40$ & $-2,7 \%$ & $-4,1 \%$ \\
\hline CZ - SK & $-111,6 \%$ & $-1,33$ & $-3,08$ & 3,48 & 4,03 & $6,3 \%$ & $7,3 \%$ & $-119,0 \%$ & $-12,58$ & $-18,37$ & $-0,10$ & 4,42 & $-0,1 \%$ & $3,7 \%$ \\
\hline $\mathrm{CZ}-\mathrm{AT}$ & $-81,8 \%$ & 2,31 & $-1,06$ & 5,42 & 5,52 & $5,8 \%$ & $5,9 \%$ & $42,6 \%$ & 9,12 & $-0,27$ & 9,97 & 1,17 & $4,7 \%$ & $0,6 \%$ \\
\hline $\mathrm{CZ}-50 \mathrm{~Hz}$ & $-30,5 \%$ & 7,81 & 7,77 & 13,61 & 12,06 & $39,1 \%$ & $34,7 \%$ & $70,3 \%$ & 19,52 & 18,63 & 18,33 & 17,41 & $15,4 \%$ & $14,6 \%$ \\
\hline CZ - TENNET & $-86,2 \%$ & $-1,63$ & $-3,04$ & 1,96 & 1,66 & $4,1 \%$ & $3,5 \%$ & $3,8 \%$ & $-7,04$ & $-10,95$ & $-4,44$ & $-6,28$ & $-4,6 \%$ & $-6,5 \%$ \\
\hline PL - DE & $-100,4 \%$ & 21,63 & 25,38 & 8,29 & 10,12 & $20,1 \%$ & $24,6 \%$ & $-77,0 \%$ & 66,88 & 65,90 & 39,84 & 40,68 & $45,5 \%$ & $46,5 \%$ \\
\hline $\mathrm{DE}-\mathrm{AT}$ & $-78,1 \%$ & 13,56 & 10,77 & 16,44 & 17,28 & $16,5 \%$ & $17,3 \%$ & $20,2 \%$ & 72,47 & 62,33 & 74,91 & 62,87 & $22,8 \%$ & $19,2 \%$ \\
\hline PL - SK & $-89,4 \%$ & $-2,80$ & $-3,88$ & 3,44 & 3,15 & $18,8 \%$ & $17,3 \%$ & $-34,1 \%$ & $-1,10$ & $-0,54$ & 0,67 & 0,89 & $1,3 \%$ & $1,7 \%$ \\
\hline $50 \mathrm{~Hz}-\mathrm{TENNET}$ & - & 19,56 & 14,62 & 45,95 & 40,47 & $10,6 \%$ & $9,3 \%$ & - & 4,13 & $-13,42$ & 118,59 & 90,79 & $10,7 \%$ & $8,2 \%$ \\
\hline TENNET - AMPRION & - & 14,44 & 4,86 & 63,48 & 60,55 & $14,6 \%$ & $14,0 \%$ & - & 85,20 & 79,87 & 84,52 & 87,03 & $7,7 \%$ & $8,0 \%$ \\
\hline TENNET - TransnetBW & - & 6,42 & 3,75 & 12,75 & 11,44 & $12,3 \%$ & $11,0 \%$ & - & 27,83 & 26,35 & 27,37 & 26,57 & $10,6 \%$ & $10,3 \%$ \\
\hline TransnetBW - AMPRION & - & 3,48 & 0,30 & 15,38 & 15,21 & $15,4 \%$ & $15,2 \%$ & - & 25,58 & 28,08 & 29,25 & 31,03 & $11,7 \%$ & $12,5 \%$ \\
\hline DE-N - DE-S & - & 0,50 & $-7,41$ & 53,24 & 49,41 & $14,3 \%$ & $13,3 \%$ & - & $-11,63$ & $-14,57$ & 79,38 & 72,33 & $8,6 \%$ & $7,8 \%$ \\
\hline
\end{tabular}

\subsection{North-Western Europe}

Despite the fact that North-Western Europe is not the area of our particular interest, it is very important to mention that the impact of above mentioned high VRES feed-in together with the scenarios have much more striking impact on this area than on the area of CE, specially in week 14 (fig. 8). Whilst the increases in flows of electrical current are still in manageable terms in CE, different effect can be measured on the borders of Germany and Netherlands and Germany 
Table 7: Extreme load overview

\begin{tabular}{ll|cccccc} 
& & \multicolumn{5}{c}{ \# extremes } \\
Interconnector & Substations & w4 & w4 & w4 & w14 & w14 & w14 \\
base & res & full & base & res & full \\
\hline \hline $\mathrm{PL} \Longrightarrow \mathrm{CZ}$ & Bujakow-Liskovec & - & - & - & - & 1 & - \\
$\mathrm{CZ} \Longrightarrow \mathrm{PL}$ & Liskovec-Kopanina & - & - & - & - & - & - \\
$\mathrm{PL} \Longrightarrow \mathrm{CZ}$ & Wielopole-Nosovice & - & - & - & - & - & - \\
$\mathrm{CZ} \Longrightarrow \mathrm{PL}$ & Albrechtice-Dobrzen & - & - & - & - & - & - \\
$\mathrm{SK} \Longrightarrow \mathrm{CZ}$ & Varin-Nosovice & - & - & - & - & - & - \\
$\mathrm{CZ} \Longrightarrow \mathrm{AT}$ & Slavetice-Durnrohr & - & - & - & - & - & - \\
$\mathrm{CZ} \Longrightarrow \mathrm{SK}$ & Sokolnice-Stupava & - & - & - & - & - & - \\
$\mathrm{CZ} \Longrightarrow \mathrm{SK}$ & Sokolnice-Krizovany & - & - & - & - & - & - \\
$\mathrm{CZ} \Longrightarrow \mathrm{AT}$ & Sokolnice-Bisamberg & - & - & - & - & - & - \\
$\mathrm{SK} \Longrightarrow \mathrm{CZ}$ & Povazska Bystrica-Liskovec & - & - & - & - & - & - \\
$\mathrm{SK} \Longrightarrow \mathrm{CZ}$ & Senica-sokolnice & - & - & - & - & - & - \\
$\mathrm{CZ} \Longrightarrow \mathrm{Tennet}$ & Hradec II-Etzenricht & - & - & - & - & - & - \\
$\mathrm{CZ} \Longrightarrow 50 \mathrm{Hertz}$ & Hradec I-Rohrsdorf & - & - & - & - & - & - \\
$\mathrm{CZ} \Longrightarrow \mathrm{Tennet}$ & Prestice-Etzenricht & - & - & - & - & - & - \\
$\mathrm{PL} \Longrightarrow \mathrm{SK}$ & Lemesany-Krosno Iskrzynia & - & - & - & - & - & - \\
$\mathrm{DE} \Longrightarrow \mathrm{AT}$ & Aux-Oberbayern-Burs & - & - & - & - & 3 & 8 \\
$\mathrm{DE} \Longrightarrow \mathrm{AT}$ & Vohringen West-Burs & - & - & - & - & - & - \\
$\mathrm{AT} \Longrightarrow \mathrm{DE}$ & Burs-Obermorrweiler & - & - & - & - & - & - \\
$\mathrm{DE} \Longrightarrow \mathrm{AT}$ & Obermorrweiler-Burs & - & - & - & - & - & - \\
$\mathrm{DE} \Longrightarrow \mathrm{AT}$ & Pirach-Sankt Peter & - & - & - & - & - & - \\
$\mathrm{DE} \Longrightarrow \mathrm{AT}$ & Altheim-Sankt Peter & - & - & - & - & - & - \\
$\mathrm{DE} \Longrightarrow \mathrm{AT}$ & Simbach-Sankt Peter & - & - & - & 1 & 3 & 3 \\
$\mathrm{DE} \Longrightarrow \mathrm{AT}$ & Pleinting-Sankt Peter & - & - & - & - & 6 & 3 \\
$\mathrm{DE} \Longrightarrow \mathrm{AT}$ & Leupolz-Westtirol & - & - & - & - & - & - \\
$\mathrm{DE} \Longrightarrow \mathrm{AT}$ & Leupolz-Westtirol & - & - & - & - & - & - \\
$\mathrm{AT} \Longrightarrow \mathrm{DE}$ & Burs-Grunkraut & - & - & - & - & - & - \\
$\mathrm{DE} \Longrightarrow \mathrm{AT}$ & Pleinting-Sankt Peter & - & - & - & - & 6 & 3 \\
$\mathrm{AT} \Longrightarrow \mathrm{DE}$ & Sankt Peter-Pirach & - & - & - & - & - & - \\
$\mathrm{PL} \Longrightarrow \mathrm{DE}$ & Mikulowa-Neuerbau & - & - & - & - & 1 & 3 \\
$\mathrm{PL} \Longrightarrow \mathrm{DE}$ & Krajnik-Vierraden & 1 & - & - & 13 & 46 & 40 \\
\hline $\mathrm{Source}$ & Own & & & & & & \\
\hline & & & & &
\end{tabular}

and France for example. Especially in the former case, the lines are hitting their limits almost continuously. Altogether 4 interconnectors connect Netherlands and Germany. These lines are subject to very high average load ranging from $57 \%$ to $75.5 \%$. Also, 257 critical events occurred in the base scenario which increased about another 49 when full scenario is considered. Slightly better situation can be seen in the latter case of German-French borders. After all, these amounts represent very critical values for the system manageability and stability.

\section{Conclusion}

The overall novelty of this paper lies in the enrichment of current literature on transmission networks in Central Europe which is generally very sparse. According to our knowledge, this paper is the first to conduct the detailed load flow analysis for CE region using the ELMOD model, in which the same degree of detail of the grid was modelled not only for Germany but also for remaining CE countries. Additionally, the result that nuclear phase-out does not exacerbate 
the grid overloading is of great importance as it goes against widely accepted conventional knowledge.

The paper thoroughly examined power and transmission systems in Central Europe. Three key issues were identified: i) the capacity of the grid in Germany does not correspond to the needs emerging from Energiewende which creates grid bottlenecks between northern and southern Germany, ii) this induces the electricity to flow through the energy systems of neighbouring states and iii) current market design in the form of German-Austrian bidding zone further exacerbates the problems.

Our analysis revealed several important findings. First of all, the higher is the feed-in of solar and wind power plants, the higher is the exchange balance and total transport of electricity between TSO areas. This holds for international cross-border profiles as well as for inner-Germany's ones. The rise in flows leads also to increase in number of critical events which directly endanger grid stability. Furthermore, model results fit the real values much better under the peak VRES production. This is important feature of the model as the high amounts of volatile inflows are of substantial importance when examining transmission grids. Additional analysis found that while the situation remains manageable in CE, the North-Western Europe should be concerned about this issue much more.

Two scenario developments, full and res, were examined. The first one attempted to measure the ceteris paribus effect of German Energiewende on the transmission networks, especially in the context of CE. The latter one dropped out nuclear phase-out and thus assessed isolated ceteris paribus impact of increased solar and wind power production.

In the case of res, all expectation were met. Amount of cross- border transmission grew both on intra-national lines as well as on the cross-zonal ones; so did the average load on majority of particular lines. Moreover, significant rise in volatility of flows was observed.

Our case of full scenario revealed that nuclear phase-out does not significantly 
contribute to the amount of transmission as well as to the average load on lines; instead, these remain almost unchanged or slightly decrease. Reasoning for this behaviour lies presumably in the merit order effect. On the other hand, our results suggest that volatility grows as nuclear plants are shut down. This is in accordance with intuition as the nuclear power plants supply stable base-load output.

Finally, focusing on separate peaks in solar and wind production showed that the combination of high solar and low wind feed-in induces greater volatility and cross-border flows on the Czech-Austrian and German-Austrian borders. This finding is critical as it is predicted that solar power will be economically viable without subsidies within the 30 years horizon (Torani et al. 2016). A sky-rocketing increase in installed capacity can thus be expected.

On the contrary, low solar and high wind production leads to the highest observed flows within Germany as well as on transnational lines, except the ones on German-Austrian borders. Thus, electricity loop flows through other CE countries take up on intensity.

Our results also indicate new questions for further research. The ceteris paribus changes could be replaced by incorporation of parameters and variables according to the energy conceptions of all relevant countries, perfect competition and one TSO assumption could be replaced by oligopolistic structures backed by game theoretic approach and external social planner could be replaced by political institutions.

\section{Appendix A. Mathematical formulation}

The objective function of the model maximizes social welfare

$$
\max _{g, q} \sum_{T} \sum_{N}\left(\left(A_{n t} q_{n t}+\frac{1}{2} D_{n t} q_{n t}^{2}\right)-\sum_{C} g_{n c t} M_{n c}\right)
$$


where $A_{n t}$ is non-negative intercept and $D_{n t}$ is negative slope coefficient which are used to estimate the linear inverse demand function:

$$
\pi_{n t}\left(q_{n t}\right)=A_{n t}+D_{n t} q_{n t}
$$

Supply function is also linearized. The marginal cost function $m_{n c t}\left(g_{n c t}\right)$ is replaced by the coefficient $M_{n c}$ determining the time-invariant marginal cost of generation for each individual power plant unit $c$ at node $n$ based on the model data.

When solving Eq. 1 several energy balance constraints have to be accounted for. The nodal balance constraint has to be true for any node at any point in time:

$$
\sum_{c} g_{n c t}+G_{n t}^{w i n d}+G_{n t}^{\text {solar }}+P S P_{n t}^{\text {out }}-P S P_{n t}^{i n}+\sum_{n n} \theta_{n n, t} B_{n, n n}-q_{n t}=0 \quad \forall n, t .
$$

The electricity production from power plant is bounded by the installed capacity of given production unit and cannot exceed this value:

$$
g_{n c t} \leq G_{c t}^{\max } \quad \forall n, c, t
$$

Electricity flows are modeled by

$$
p_{l t}=\sum_{n} H_{l n} \theta_{n t} \quad \forall l, t
$$

Inequality (6) takes into account the capacity limits of individual transmission lines and restricts the modelled flow to respect these upper and lower bounds respectively.

$$
\left|p_{l t}\right| \leq \bar{P}_{l} \quad \forall l, t
$$

The equation (7) sets the voltage angle of an arbitrary node, called slack node, to be zero which is important because uniqueness of solution of the system is thus 
guaranteed. Due to the setting of the voltage angle of one variable, all other angle values are relative to this specific one.

$$
\begin{gathered}
\theta_{n^{\prime} t}=0 \quad \forall n, t . \\
P_{j k}=B_{j k} \theta_{j k} .
\end{gathered}
$$

Last steps in obtaining desired result in form of particular line flow incorporate the identification of nodes $n, n n$ and mapping to the lines. For this purpose, Leuthold et al. (2012) uses a special matrix, incidence matrix $I_{l n}$, which is defined followingly:

$$
I_{l n}= \begin{cases}1 & \text { if } n=j \\ -1 & \text { if } n=k \\ 0 & \text { else. }\end{cases}
$$

With the help of series line susceptance $B_{l n}$, final line power flow (5) can be obtained:

$$
\begin{gathered}
H_{l n}=B_{l n} I_{l n} \\
p_{l t}=\sum_{n} H_{l n} \theta_{n t} .
\end{gathered}
$$

Referring to the previous text on net input, technical description is added. Net input variable is determined by network susceptance matrix and voltage angles $\nu_{n t}=\sum_{n n} B_{n, n n} \theta_{n n, t}$. Mathematical derivation of the first parameter, the susceptance matrix $B_{n, n n}$, is based on above mentioned flow definitions (Leuthold et al. 2012).

$$
B_{n, n n}=\sum_{l} I_{l n} H_{l n}
$$


Sets and indices:

$L$

$N$

C

T

$l \in L$

$n, n n \in N$

$n^{\prime} \in N$

$c \in C$

$t \in T$ set of all lines

set of all nodes

set of all conventional plants

set of all time periods

line within the network

nodes within the network

slack node(s) within the network

conventional power plant unit

time periods

Parameters:

$G_{n t}^{\text {wind }}$

$G_{n t}^{\text {solar }}$

$P S P_{n t}^{o u t}$

$P S P_{n t}^{i n}$

$G_{c t}^{\max }$

$\bar{P}_{l t}$

$H_{l n}$

$B_{n, n n}$

$A_{n t}$

$D_{n t}$

$M_{n c}$

Variables:

$w$

$\pi_{n t}\left(q_{n t}\right)$

welfare function

$m_{n c t}\left(g_{n c t}\right)$

$g_{\text {nct }}$

$q_{n t}$

$\nu_{n t}$

$p_{l t}$

$\theta_{n t}, \theta_{n n, t}, \theta_{n^{\prime} t}$ wind input at node $n$ in time $t$

solar input at node $n$ in time $t$

pump storage plant release at node $n$ in time $t$

pump storage loading at node $n$ in time $t$

maximal generation of generation unit $c$ in time $t$

maximal available capacity limit of line $l$ in time $t$

network transfer matrix

network susceptance matrix

intercept coefficient at node $n$ in time $t$

slope coefficient at node $n$ in time $t$

marginal cost coefficient of power plant unit $c$ at node $n$

inverse demand function at node $n$ in time $t$

marginal cost of generation of plant $c$ at node $n$ in time $t$ generation of generation unit $c$ at node $n$ in time $t$

demand at node $n$ in time $t$

net input to node $n$ in time $t$

power flow over line $l$ in time $t$

flow angle at node $n$ in time $t$ 


\section{References}

Abrell, J. \& F. KunZ (2012): "Integrating intermittent renewable wind generationinsights from the stochastic electricity market model (stELMOD." Electricity Markets Working Paper WP-EM-49, Dresden University of Technology.

ACER (2015): "Opinion of the Agency for the Cooperation of Energy Regulators No 9/2015 of 23 September 2015." http://www.acer.europa. eu/official_documents/acts_of_the_agency/opinions/opinions/acer\% 20opinion\%2009-2015.pdf. [Online; accessed 22-April-2016].

AGEB (2015): "Bruttostromerzeugung in Deutschland ab 1990 nach Energieträgern." Technical report, AG Energiebilanzen, e.V.

APG (2015): "Network development plan 2015." https://www.apg.at/ /media/ A74BB5124C2545EAB85F15BF946BA036.pdf. [Online; accessed 22-April-2016].

Bemš, J., T. Králík, J. Knápek, \& A. Kradeckaia (2016): "Bidding zones reconfiguration - current issues literature review, criterions and social welfare." In "2nd International Conference on Intelligent Green Building and Smart Grid (IGBSG)," pp. 1-6.

Blest, M., A. Das, U. Fahl, \& U. Remme (2007): "Role of energy efficiency standards in reducing CO2 emissions in Germany: An assessment with TIMES." Energy Policy 35(2): pp. 772-785.

BMWi (2015a): An electricity market for Germany's energy transition - White Paper by the Federal Ministry for Economic Affairs and Energy. Budnesministerium für Wirtschaft und Energie.

BMWI (2015b): Die Energie der Zukunft: Vierter Monitoringbericht zur Energiewende. Budnesministerium für Wirtschaft und Energie.

BMWI (2015c): "Um diese Projekte geht es beim Netzausbau." https: //www.bmwi-energiewende.de/EWD/Redaktion/Newsletter/2015/9/Meldung/ infografik-netzausbauprojekte.html. [Online; accessed 22-April-2016].

BMWI (2016): "Strommarkt der Zukunft - Zahlen und Fakten." http://www. bmwi. de/DE/Themen/Energie/Strommarkt-der-Zukunft/zahlen-fakten.html. [Online; accessed 22-April-2016]. 
Bundesnetzagentur (2015): "Why is the grid expansion necessary." http://www . netzausbau.de/EN/background/why/en.html. [Online; accessed 22-April-2016].

Bundesnetzagentur (2016): "Leitungsvorhaben." http://www.netzausbau.de/ leitungsvorhaben/de.html. [Online; accessed 22-April-2016].

Burstedde, B. (2012): "From nodal to zonal pricing: A bottom-up approach to the second-best." In "9th International Conference on the European Energy Market (EEM)," pp. 1-8. IEEE.

ČEPS (2010): "Souhrnná zpráva ČEPS, a.s., za rok 2010." http://www.ceps.cz/ CZE/O-spolecnosti/Hospodarske-vysledky/Documents/Souhrnna_zprava_rok_ 2010.pdf. [Online; accessed 22-April-2016].

ČEPS (2015): "Development Plan for the Transmission System of the Czech Republic 2015 - 2024." http://www.ceps.cz/ENG/Cinnosti/Technicka-infrastruktura/ Documents/Development\%20Plan\%202015-2024.pdf. [Online; accessed 22-April2016].

ČEPS (2016): "Transmission system development." http://www.ceps.cz/ENG/ Cinnosti/Technicka-infrastruktura/Pages/Rozvoj-PS. aspx. [Online; accessed 22-April-2016].

Cludius, J., H. Hermann, F. C. Matthes, \& V. Graichen (2014): "The merit order effect of wind and photovoltaic electricity generation in Germany 2008-2016: Estimation and distributional implications." Energy Economics 44: pp. 302-313.

Dietrich, K., F. Leuthold, \& H. Weigt (2010): "Will the market get it right? The placing of new power plants in Germany." Zeitschrift für Energiewirtschaft 34(4): pp. 255-265.

E-CONTROL (2016): "Statistikbrochüre 2015." http://www.e-control. at/documents/20903/388512/e-control-statistikbroschuere-2015.pdf / 59782e4b-3b3c-4cb0-8591-ee45c29815ce. [Online; accessed 22-April-2016].

Egerer, J., L. Bückers, \& G. Drondorf (2009): "Sustainable energy networks for Europe-The integration of large-scale renewable energy sources until 2050." Dresden Universisty of Technology, and Chair for Energy Economics and Public Sector Management . 
Egerer, J., C. Gerbaulet, R. Ihlenburg, F. Kunz, B. Reinhard, C. von Hirschhausen, A. Weber, \& J. Weibezahn (2014): "Electricity sector data for policy-relevant modeling: Data documentation and applications to the German and european electricity markets." Technical report, Data Documentation, DIW.

Egerer, J., C. Lorenz, \& C. Gerbaulet (2016a): "European electricity grid infrastructure expansion in a 2050 context." The Energy Journal forthcoming.

Egerer, J., J. Weibezahn, \& H. Hermann (2016b): "Two Price Zones for the German Electricity Market: Market Implications and Distributional Effects." Energy Economics 59: pp. 365-381.

EGÚ BRno (2010): "Bezpečná integrace OZE do ES ČR.” https://www.cez.cz/ edee/content/file/pro-media/prezentace_csres_10_03_2010.pdf. [Online; accessed 22-April-2016].

Energy Regulatory Office (2015): "Yearly Report on the Operation of the Czech Electricity Grid for 2014." http://www.eru . cz/documents/10540/462820/Annual_report_electricity_2014.pdf/ f23d80b5-668a-42c0-9d04-1a19556c9c58. [Online; accessed 22-April-2016].

ENTSOE (2016): "ENTSOE Transpareny Platform." https://transparency . entsoe.eu/. [Online; accessed 22-April-2016].

Eser, P., A. Singh, N. Chokani, \& R. S. Abhari (2015): "High resolution simulations of increased renewable penetration on central European transmission grid." In "Power \& Energy Society General Meeting, 2015 IEEE," pp. 1-5. IEEE.

European Commission (2009): "Directive 2009-28-EC of the European Parliament and of the Council of 23 April 2009 on the promotion of the use of energy from renewable sources and amending and subsequently repealing Directives 2001-77-EC and 2003-30." Off. J. of the EU, European Commission 5: pp. 16-62.

European Commission (2014): "Communication from the Commission to the European Parliament, the Council, the European Economic and Social Committee and the Committee of the Regions - A policy framework for climate and energy in the period from 2020 to 2030." http://eur-lex.europa.eu/legal-content/EN/TXT/ ?uri=COM\%3A2014\%3A15\%3AFIN. [Online; accessed 22-April-2016]. 
European Commission (2015): "European Commission - Energy Union Factsheet." http://europa.eu/rapid/press-release_MEMO-15-4485_en.htm. [Online; accessed 22-April-2016].

European Commission, DG Energy (2016a): "Country Datasheets 2016." https://ec.europa.eu/energy/sites/ener/files/documents/ CountryDatasheets_February2016.xlsx. [Online; accessed 22-April-2016].

European Commission, DG Energy (2016b): "EU Crude Oil Imports and Supply Cost." https://ec.europa.eu/energy/en/statistics/eu-crude-oil-imports. [Online; accessed 22-April-2016].

European Commission, DG Energy (2016c): "Quarterly Report on European Electricity Markets." https://ec.europa.eu/energy/en/statistics/ market-analysis. [Online; accessed 22-April-2016].

European Commission, DG Energy (2016d): "Quarterly Report on European Gas Markets." https://ec.europa.eu/energy/en/statistics/market-analysis. [Online; accessed 22-April-2016].

Feix, O., R. Obermann, M. Hermann, \& S. Zeltner (2015): Netzentwicklungsplan Strom 2015, Version 2015. Entwurf der Übertragungnetzbetreiber. CB. e Clausecker, Bingel AG, Germany.

Flechter, J. \& S. Bolay (2015): "Faktenpapier Ausbau der Stromnetze." Technical report, DIHK.

Fürsch, M., S. Hagspiel, C. Jägemann, S. Nagl, D. Lindenberger, \& E. TRÖSTER (2013): "The role of grid extensions in a cost-efficient transformation of the European electricity system until 2050." Applied Energy 104: pp. 642-652.

Green, R. (2007): "Nodal pricing of electricity: How much does it cost to get it wrong?" Journal of Regulatory Economics 31(2): pp. 125-149.

HavlíčKová, K., J. Weger, \& J. Knápek (2011): "Modelling of biomass prices for bio-energy market in the Czech Republic." Simulation Modelling Practice and Theory 19(9): pp. 1946-1956.

Huppmann, D. \& J. Egerer (2015): "National-strategic investment in European power transmission capacity." European Journal of Operational Research 247(1): pp. 191-203. 
JandA, K., Š. KrŠKA, J. PrŮŠA et al. (2014): "Czech Photovoltaic Energy: Model Estimation of The Costs of its Support." Politická ekonomie 2014(3): pp. 323-346.

Kamparth, N. B. (2016): "EU-Kommission spricht sich gegen Marktgebietsteilung aus." In: Montel.de, 20.1.2016, http://www .montel.de/StartPage/SubPage .aspx? id=669146. [Online; accessed 22-April-2016].

Keles, D., D. Möst, \& W. Fichtner (2011): "The development of the German energy market until 2030 â€" a critical survey of selected scenarios." Energy Policy 39(2): pp. 812-825.

KettereR, J. C. (2014): "The impact of wind power generation on the electricity price in Germany." Energy Economics 44: pp. 270-280.

KLos, Č. (2012): "Stop stav pro připojování obnovitelných zdroju prolomen." In: Česká pozice, 9.1.2012, http://ceskapozice.lidovky.cz/ stop-stav-pro-pripojovani-obnovitelnych-zdroju-prolomen-p3t-/tema . aspx?c=A120109_160641_pozice_52001. [Online; accessed 22-April-2016].

Kocot, H., R. Korab, W. Lubicki, M. Przygrodzki, G. Tomasik, \& K. Zmuda (2013): "Improving the cross-border transmission capacity of Polish power system by using phase shifting transformers." In "CIGRE 7th Southern Africa Regional Conference," pp. 7-11.

Korab, R. \& R. OwCZAREK (2016): "Impact of phase shifting transformers on crossborder power flows in the Central and Eastern Europe region." Bulletin of the Polish Academy of Sciences Technical Sciences 64(1): pp. 127-133.

KunZ, F. (2013): "Improving congestion management: how to facilitate the integration of renewable generation in Germany." The Energy Journal 34(4): pp. 55-79.

Kunz, F. \& A. Zerrahn (2015): "Benefits of coordinating congestion management in electricity transmission networks: Theory and application to Germany." Utilities Policy 37: pp. 34-45.

Kunz, F. \& A. Zerrahn (2016): "Coordinating Cross-Country Congestion Management." Technical report, DIW Berlin, German Institute for Economic Research.

Leuthold, F., T. Jeske, H. Weigt, \& C. Von Hirschhausen (2009): "When the Wind Blows Over Europe: A Simulation Analysis and the Impact of Grid Extensions." Available at SSRN 1328971. 
Leuthold, F., H. Weigt, \& C. v. Hirschhausen (2008): "ELMOD - a model of the European electricity market." Technical report, Electricity Markets Working Papers WPEM-00, Dresden University of Technology, Chair for Energy Economics and Public Sector Management.

Leuthold, F. U. (2009): Economic Engineering Modeling of Liberalized Electricity Markets: Approaches, Algorithms, and Applications in a European Context. Ph.D. thesis, Technische Universität Dresden, Fakultät der Wirtschaftwissenschaften.

Leuthold, F. U., H. Weigt, \& C. Von Hirschhausen (2012): "A large-scale spatial optimization model of the European electricity market." Networks and spatial economics 12(1): pp. 75-107.

Majchrzak, H., G. Tomasik, D. Owczarek, \& K. Purchąa (2013): "Crossborder unplanned flows in European power system as obstacle towards Integrated Electricity Market." In "CIGRE 7th Southern Africa Regional Conference," pp. 7-11.

Meyer, T. \& J. Luther (2004): "On the correlation of electricity spot market prices and photovoltaic electricity generation." Energy Conversion and Management 45(17): pp. 2639-2644.

Ministersvo hospodárstva Slovenskej Republiky (2015): "Správa o výsledkoch monitorovania bezpečnosti dodávok elektriny." http://www.economy.gov.sk/ uvod-energetika/129480s. [Online; accessed 22-April-2016].

Neuhoff, K., J. Barquin, J. W. Bialek, R. Boyd, C. J. Dent, F. Echavarren, T. Grau, C. Von Hirschhausen, B. F. Hobbs, F. Kunz et al. (2013): "Renewable electric energy integration: quantifying the value of design of markets for international transmission capacity." Energy Economics 40: pp. 760-772.

Neuhoff, K., J. Barquin, M. G. Boots, A. Ehrenmann, B. F. Hobbs, F. A. RiJKeRs, \& M. VAzQuez (2005): "Network-constrained Cournot models of liberalized electricity markets: the devil is in the details." Energy Economics 27(3): pp. 495525.

Overbye, T. J., X. Cheng, \& Y. Sun (2004): "A comparison of the AC and DC power flow models for LMP calculations." In "System Sciences, 2004. Proceedings of the 37th Annual Hawaii International Conference on," pp. 9-pp. IEEE. 
Pollitt, M. G. \& K. L. Anaya (2016): "Can Current Electricity Markets Cope with High Shares of Renewables? A Comparison of Approaches in Germany, the UK and the State of New York." The Energy Journal 37(0): pp. 69-89.

PrŮŠA, J., A. KlimeŠOvÁ, \& K. Janda (2013): “Consumer loss in Czech photovoltaic power plants in 2010-2011." Energy Policy 63: pp. 747-755.

PSE (2015a): "Development plan for meeting the current and future electricity demand for 2016-2025." http://www.pse.pl/uploads/kontener/Development_Plan_for_ meeting_the_current_and_future_electricity_demand_for_2016-2025.pdf. [Online; accessed 22-April-2016].

PSE (2015b): "Raport 2015 KSE." http://www .pse.pl/index .php?did=2870. [Online; accessed 22-April-2016].

Purchala, K., L. Meeus, D. Van Dommelen, \& R. Belmans (2005): "Usefulness of DC power flow for active power flow analysis." In "Power Engineering Society General Meeting, 2005. IEEE," pp. 454-459. IEEE.

RAPP, H. (2012): Energieversorgung im Wandel: Hoffnungen und Fakten zur Energiewende. Pro Business.

REČKA, L. \& M. ŠČASNÝ (2013): "Environmental regulation impacts on the Czech power system by the dynamic linear optimisation model message." Politická ekonomie 2013(2): pp. 248-273.

REČKA, L. \& M. ŠČASNÝ (2016): "Impacts of carbon pricing, brown coal availability and gas cost on Czech energy system up to 2050." Energy pp. 19-33.

ŠčasnÝ, M., V. Píšsa, H. Pollit, \& U. Chewpreecha (2009): “Analyzing Macroeconomic Effects of Environmental Taxation in the Czech Republic with the Econometric E3ME Model." Czech Journal of Economics and Finance (Finance a uver) 59(5): pp. $460-491$.

Schaber, K., F. Steinke, \& T. Hamacher (2012a): "Transmission grid extensions for the integration of variable renewable energies in Europe: Who benefits where?" Energy Policy 43: pp. 123-135.

Schaber, K., F. Steinke, P. Mühlich, \& T. Hamacher (2012b): "Parametric study of variable renewable energy integration in Europe: Advantages and costs of transmission grid extensions." Energy Policy 42: pp. 498-508. 
Schröder, A., F. Kunz, J. Meiss, R. Mendelevitch, \& C. Von Hirschhausen (2013): "Current and prospective costs of electricity generation until 2050." DIW Data Documentation 68: p. 104.

Schroeder, A., P.-Y. Oei, A. Sander, L. Hankel, \& L. C. Laurisch (2013): "The integration of renewable energies into the German transmission grid - A scenario comparison." Energy Policy 61: pp. 140-150.

Schubert, D. K. J., T. Meyer, \& D. Möst (2015a): "Die Transformation des deutschen Energiesystems aus der Perspektive der Bevölkerung." Zeitschrift für Energiewirtschaft 39(1): pp. 49-61.

Schubert, D. K. J., S. Thuss, \& D. Möst (2015b): "Does political and social feasibility matter in energy scenarios?" Energy Research 6 Social Science 7: pp. 43-54.

Schweppe, F. C., M. C. Caramanis, R. D. Tabors, \& R. E. Bohn (1988): Spot pricing of electricity. Springer Science \& Business Media.

SEPS (2014): "Ten year network devepolment plan for the period 2015 - 2024 ."http://www.sepsas.sk/seps/Dokumenty/ProgRozvoj/2015/04/DPR_PS_2015_ 2024_en.pdf. [Online; accessed 22-April-2016].

Singh, A., T. Frei, N. Chokani, \& R. S. Abhari (2016): "Impact of unplanned power flows in interconnected transmission systems-Case study of Central Eastern European region." Energy Policy 91: pp. 287-303.

Singh, A., D. Willi, N. Chokani, \& R. S. Abhari (2015): "Increasing On-Shore Wind Generated Electricity in Germany's Transmission Grid." Journal of Engineering for Gas Turbines and Power 137(2): p. 021801.

Stigler, H. \& C. Todem (2005): "Optimization of the Austrian electricity sector (Control Zone of VERBUND APG) by nodal pricing." Central European Journal of Operations Research 13(2): p. 105.

Torani, K., G. Rausser, \& D. Zilberman (2016): "Innovation subsidies versus consumer subsidies: A real options analysis of solar energy." Energy Policy 92: pp. $255-269$.

Traber, T. \& C. Kemfert (2009): "Impacts of the German support for renewable energy on electricity prices, emissions, and firms." The Energy Journal pp. 155-178. 
ČEPS, MAVIR, PSE OPERATor, \& SEPS (2012): "Position of ČEPS, MAVIR, PSE Operator and SEPS regarding the issue of Bidding Zones Definition."

Vrba, M., Z. ŠpaČek, J. Jež, \& J. PtÁČEK (2015): "Integration of Electricity from Renewable Energy Sources - The Czech Story." Energy 83 Environment 26(1-2): pp. 157-166.

Weigt, H., T. Jeske, F. Leuthold, \& C. von Hirschhausen (2010): "Take the long way down: Integration of large-scale North Sea wind using HVDC transmission." Energy Policy 38(7): pp. 3164-3173.

Winkler, J., A. Gaio, B. Pfluger, \& M. Ragwitz (2016): "Impact of renewables on electricity markets-Do support schemes matter?" Energy Policy 93: pp. 157-167. 